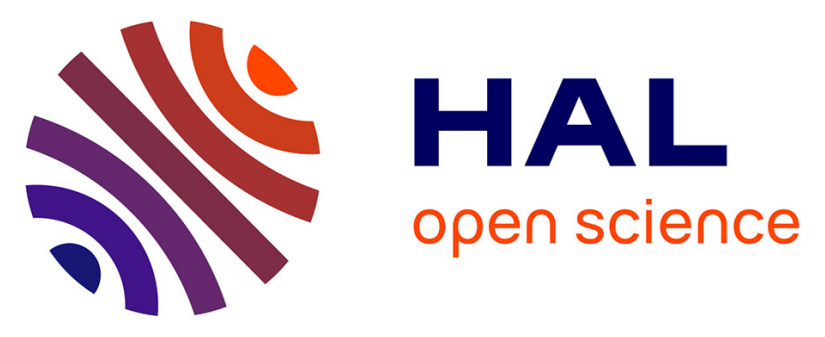

\title{
Rapid morphological changes, admixture and invasive success in populations of Ring-necked parakeets (Psittacula krameri) established in Europe
}

Ariane Le Gros, Sarah Samadi, Dario Zuccon, Raphaël Cornette, Michael P. Braun, Juan Carlos Senar, Philippe Clergeau

\section{To cite this version:}

Ariane Le Gros, Sarah Samadi, Dario Zuccon, Raphaël Cornette, Michael P. Braun, et al.. Rapid morphological changes, admixture and invasive success in populations of Ring-necked parakeets (Psittacula krameri) established in Europe. Biological Invasions, 2016, 18 (6), pp.1581-1598. 10.1007/s10530016-1103-8 . hal-01291981

\section{HAL Id: hal-01291981 \\ https: / hal.sorbonne-universite.fr/hal-01291981}

Submitted on 22 Mar 2016

HAL is a multi-disciplinary open access archive for the deposit and dissemination of scientific research documents, whether they are published or not. The documents may come from teaching and research institutions in France or abroad, or from public or private research centers.
L'archive ouverte pluridisciplinaire HAL, est destinée au dépôt et à la diffusion de documents scientifiques de niveau recherche, publiés ou non, émanant des établissements d'enseignement et de recherche français ou étrangers, des laboratoires publics ou privés. 


\title{
Rapid morphological changes, admixture and invasive success in populations of Ring- necked parakeets (Psittacula krameri) established in Europe.
}

\author{
Ariane Le Gros ${ }^{1,2,5 *}$, Sarah Samadi ${ }^{2}$, Dario Zuccon², Raphaël Cornette ${ }^{2}$, Michael P. Braun ${ }^{3}$,
} Juan Carlos Senar ${ }^{4}$, and Philippe Clergeau ${ }^{5}$

\section{Biological Invasions - ISSN 1387-3547 - SPRINGER \\ DOI 10.1007/s10530-016-1103-8}

The final publication is available at http://link.springer.com/article/10.1007\%2Fs10530-016$1103-8$

\author{
${ }^{1}$ Université Paris Diderot, Sorbonne Paris Cité, 5 Rue Thomas Mann, 75013 Paris, France \\ ${ }^{2}$ Institut de Systématique, Evolution, Biodiversité (ISYEB UMR 7205), Sorbonne \\ Universités, MNHN, CNRS, UPMC, CP26, 57 rue Cuvier, 75005 Paris, France \\ ${ }^{3}$ Institute of Pharmacy and Molecular Biotechnology, Heidelberg University, Im Neuenheimer \\ Feld 364, D-69120 Heidelberg, Germany \\ ${ }^{4}$ Evolutionary and Behavioural Ecology Associate Research Unit (CSIC), Natural History \\ Museum of Barcelona, Passeig Picasso s/n, 08003 Barcelona, Spain \\ ${ }^{5}$ Centre d'Ecologie et des Sciences de la Conservation (CESCO UMR7204), Sorbonne \\ Universités, MNHN, CNRS, UPMC, CP51, 55 rue Buffon, 75005, Paris, France \\ *Corresponding author: ariane.le.gros@gmail.com
}

\begin{abstract}
The Ring-necked parakeet (Psittacula krameri), native of Asia and Africa, is a very successful invasive species in Europe: it has been present there for over 50 years. A recent study showed that European invasive populations occupy a colder climatic niche than in their native range but the establishment of this tropical species in temperate regions remains unexplained. Two main hypotheses may explain the success of Ring-necked parakeet in Europe: admixture between individuals from different origins and/or rapid adaptation to new environmental conditions. In this study, we investigated with molecular data the origin of European populations of Ring-necked parakeets to assess whether these populations result from admixture between individuals from different source populations. We also investigated the morphology of individuals from European populations and from the native range to assess whether the invasive populations have morphologically diverged from their source and could have become adapted to European conditions. We found evidence of admixture in some of the European populations but not all of them. Admixture between individuals from different origins within European populations thus cannot explain alone their invasive success. Conversely, we found that the morphology of the individuals from European populations has diverged from the morphology of native individuals, in a similar direction. Rapid adaptation to European environmental conditions via phenotypic plasticity or natural selection could thus be a factor explaining the invasive success of Ring-necked parakeets in Europe.
\end{abstract}

Key-words: admixture, morphometrics, phylogeography, population genetics, rapid adaptation, Ring-necked parakeet 


\section{Introduction}

The Ring-necked parakeet (Psittacula krameri) is a popular cage bird that has been introduced accidentally in many countries since the 1960 s. It is a very successful invasive species especially in Europe where populations of Ring-necked parakeets have become established in periurban areas of big cities. They were observed to breed in Belgium (first observation: 1966), the Netherlands (1968), Great Britain (1969), Germany (1969), France (1970s), Italy (1970s), Spain (1982), Portugal (1986), and Greece (1992, Braun 2009). These populations have rapidly grown and the total number of individuals was estimated at 29,000 in 2008 (Braun 2009). The Ring-necked parakeet is native from the Indian subcontinent and sub-Saharan Africa (del Hoyo et al. 1997). Four sub-species have been described, based on coloration patterns and size differences (del Hoyo et al. 1997): two in Asia and two in Africa (figure 1). Despite established populations have been present in Europe for more than 50 years, the origin of these populations has long been uncertain and is still unclear in some aspects. CITES trade data show that between 1981 and 2012, comparable amounts of Ring-necked parakeets have been imported in Europe from Africa and from Asia with variable proportions according to countries (CITES 2015, about $40 \%$ and $55 \%$ of the total importations respectively, table 1 ). Trade data are not available for the period before 1981 . However, a study conducted in the United Kingdom showed that established individuals have a morphology and a beak coloration more similar to the two Asian subspecies than to the African subspecies (Butler 2003) and it was hypothesized that populations established in the United Kingdom derive from a mixture of the two Asian subspecies (Morgan 1993; Pithon and Dytham 2001). In this case, it would mean that the establishment success of the Asian subspecies is, for some reasons, higher than the establishment success of the African subspecies.

A more recent study based on mitochondrial sequences also showed that most haplotypes found in European populations are close or similar to haplotypes found in Asian specimens and that both Indian subspecies seemed to be represented in European populations (Jackson et al. 2015). However, the results of this study do not allow the distinction of the two Asian subspecies and it is thus not possible to know more precisely the origin of European populations within Asia. In addition, based on a populations genetics analysis conducted on ten microsatellite markers, the authors suggested that individuals established in Europe share polymorphism with African samples and concluded that individuals from Africa could also have established in Europe (Jackson et al. 2015). However, this is uncertain as the output of this population genetics analysis showed that Asian specimens also share some polymorphism with African ones. Therefore, the cluster assignations obtained for European populations could be explained by an Asian origin only. In addition, examination of the raw data used in this analysis revealed a very high proportion of missing data, especially for samples from the native range, that could have distorted the results.

Besides the origin of European populations, the establishment success of Ring-necked parakeets in temperate regions is also puzzling and has been the subject of several studies (Shwartz et al. 2009; Strubbe and Matthysen 2009; Clergeau and Vergnes 2011; Strubbe et al. 2015). The "climate-matching" hypothesis has been recurrently proposed to explain this success. It states that species have a higher probability of establishing if they are introduced into regions with a climate similar to the climate of their native area (Shwartz et al. 2009; Strubbe and Matthysen 2009). Indeed, a species experiencing environmental conditions that are similar in its native and invasive range, 


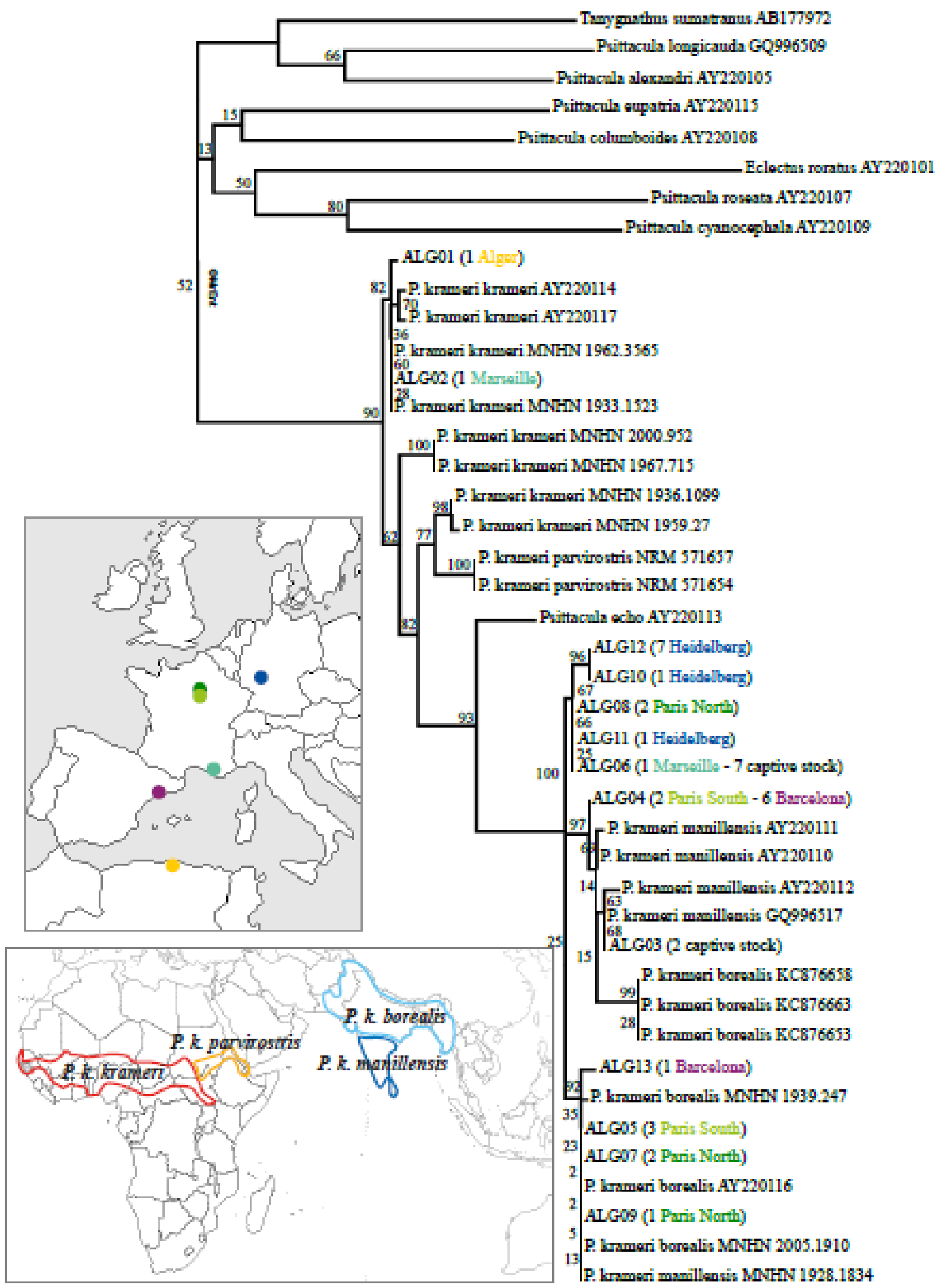

Fig. 1 The majority rule consensus tree obtained from the Bayesian analysis of the cytochrome $b$ gene. The support values indicated at the node are the bootstrap support obtained from the maximum likelihood analysis. Colors refer to the invasive populations where individuals were sampled (represented on the map of Europe). 
Table 1: Origin of Ring-necked parakeets imported to Western Europe between 1981 and 2012 for each country.

\begin{tabular}{cccccc} 
Importing country & Africa (NR) & Asia (NR) & Outside of NR & Unknown origin & Total counts \\
\hline Italy & $20.66 \%$ & $75.32 \%$ & $4.01 \%$ & $0 \%$ & 146733 \\
Spain & $23.37 \%$ & $72.87 \%$ & $3.76 \%$ & $0 \%$ & 71478 \\
Portugal & $76.43 \%$ & $10.60 \%$ & $12.95 \%$ & $0.02 \%$ & 57842 \\
Great Britain & $52.93 \%$ & $33.80 \%$ & $13.21 \%$ & $0.06 \%$ & 24105 \\
Germany & $80.70 \%$ & $17.65 \%$ & $1.66 \%$ & $0 \%$ & 19757 \\
Belgium & $42.95 \%$ & $28.64 \%$ & $28.40 \%$ & $0 \%$ & 18092 \\
Greece & $9.56 \%$ & $87.56 \%$ & $2.88 \%$ & $0 \%$ & 12763 \\
France & $75.73 \%$ & $23.65 \%$ & $0.62 \%$ & $0 \%$ & 12490 \\
Netherlands & $35.46 \%$ & $62.68 \%$ & $1.84 \%$ & $0.03 \%$ & 11767 \\
Denmark & $72.78 \%$ & $25 \%$ & $2.22 \%$ & $0 \%$ & 1080 \\
Switzerland & $54.96 \%$ & $0 \%$ & $26.09 \%$ & $18.95 \%$ & 897 \\
All countries & $38.15 \%$ & $54.99 \%$ & $6.80 \%$ & $0.05 \%$ & 377004 \\
\hline
\end{tabular}

NR: native range. These figures were calculated form the data extracted of the CITES trade data base (CITES 2015) for the 1975-2014 period and for all Psittacula krameri subspecies.

is supposedly "pre-adapted" to the conditions of its invasive range and is thus more able to develop there than in regions where it would need to adapt to new conditions. In Asia, the Ring-necked parakeet is found in tropical regions but also in more temperate areas. Indeed, the subspecies $P$. $k$. borealis is found in the Himalayan foothills up to the altitude of 1,600 $\mathrm{m}$ (Parr and Juniper 2010). It was thus suggested that individuals from the North of the Asian range might be adapted to cold climatic conditions matching those found in Europe (Shwartz et al. 2009; Strubbe and Matthysen 2009). Strubbe et al. (2015) however showed that the overlap between the climatic niche of native (African and Asian) and invasive populations is low and that European populations have $87 \%$ of their distribution outside their native climatic niche, inhabiting regions much colder than in their native range. Indeed, the climate of Northern Europe does not seem to be the optimum climate for the Ring-necked parakeet as Shwartz et al. (2009) show that its reproductive success was lower in the United Kingdom than in an invasive population in Israël and than in the native Indian range. It therefore seems that climate-matching is not a good hypothesis to explain the invasive success of the Ringnecked parakeet in Europe.

Admixture between groups of individuals from different origins has been showed to favor the establishment of invasive species in new locations by increasing the genetic diversity in populations and thus providing them with new evolutionary potential (Dlugosch and Parker 2008; Facon et al. 2008; Kolbe et al. 2008; Verhoeven et al. 2011). This scenario could explain the invasive success of the Ring-necked parakeet in Europe. In addition, many studies have identified cases of rapid phenotypic changes in introduced populations (e.g. Losos et al. 1997; Stockwell \& Weeks 1999; Kristjánsson et al. 2002; Yonekura et al. 2007; Dlugosch \& Parker 2008; Kooyers \& Olsen 2012; Adachi et al. 2012; Rollins et al. 2015) and it has been suggested that rapid local adaptation is also a factor favoring the establishment and spread of invasive species (Lee 2002; Lee and Gelembiuk 2008).

In this article, we aimed at investigating the hypotheses of admixture and rapid local adaptation to see whether they can explain the invasive success of the 
Ring-necked parakeet in Europe. We first used a phylogeographic approach based on mitochondrial markers to identify the general geographic origin of the European populations. Our sampling included populations that were not sampled by Jackson et al. (2015). We then used a population genetics approach based on 18 microsatellite markers to investigate the recent origins of individuals and the presence of admixture events between individuals of different origins in the European populations. If admixture was a factor explaining invasive success of the Ring-necked parakeet in Europe, we expected to find evidence of multiple introductions from different sources and admixture in every population, whereas if it was not a necessary factor we did not expect to find it in all populations. Finally, we compared the phenotype of individuals coming from three European populations and from the native range to assess whether European individuals have diverged from the individuals of their source populations. The phenotypic traits we studied were the morphology of the beak, tail and wings. Indeed, the conformation and size of the beak is known to be closely associated to the type of food item consumed by birds (e.g. Boag and Grant (1981); Leisler and Winkler (1985); Herrel et al. (2005)) and we expected that the food items consumed by parakeets in their native range differed from those consumed in the invasive range. In addition, the morphology of the wings and tail is associated to different flight abilities and thus to different habitat types (Leisler and Winkler 1985; Desrochers 2010). Finally, morphology can be measured on live individuals as well as museum specimens which allowed us to study the phenotype of individuals from the native range. If rapid morphological adaptation to European conditions (food and habitat type) was a factor explaining the invasive success of the Ring-necked parakeet, we expected to find a convergent evolution of morphology in European populations.

\section{Material and Methods}

\section{Sampling}

For the phylogeographic study, toe-pads were obtained from eleven museum specimens collected in the native range (table S1). Ten sequences available on Genbank were also added to cover the whole native range (table S1). The four currently recognized subspecies were thus represented. Feathers or blood samples were obtained from 28 individuals of 5 European populations (North of Paris (France) 5 individuals, South of Paris (France) 5 ind., Heidelberg (Germany) 9 ind., Barcelona (Spain) 7 ind., and Marseille (France) 2 ind.). In order to compare European populations with another invasive population outside of Europe, a sample from Alger (Algeria) was added. Nine individuals from a captive stock near Bordeaux (France) were also added to determine whether captive stocks and invasive populations have similar origin and if there are connections between them (table S1). The owner of the captive stock declared that his birds were of Asian origin. Finally, mitochondrial sequences published by Jackson et al. (2015) and which cover the native range and additional European populations (Amsterdam, Bonn, Brussels, Dusseldorf, London, Madrid, Rotterdam, Seville, The Hague, Tuscany, Utrecht and Wiesbaden) were also used to complement our phylogeographic study. For the population genetics study, feathers or blood samples were obtained from seven populations: North of Paris $(n=45)$, South of Paris $(n=49)$, Heidelberg $(n=30), \quad$ Barcelona $(n=40)$, Marseille $(n=3)$, Alger $(n=3)$, and the captive stock previously mentioned $(n=19)$. Microsatellite data published by Jackson et al. (2015) and covering the native range and additional European populations (Amsterdam, Bonn, Brussels, Dusseldorf, London, Rotterdam, Seville, 
The Hague and Wiesbaden) were also used to complement our population genetics analysis. For the morphological study, body measurements and standardized pictures of the beak of individuals were taken on about 400 Ring-necked parakeets by the same person (ALG). Individuals from the native range were measured in the collections of the Muséum National d'Histoire Naturelle and the British Museum of Natural History $(P . \quad k$. krameri $=105, P . k$. parvirostris $=14, P . k$. manillensis $=63, \quad P . \quad k . \quad$ borealis=130). Individuals from invasive populations were captured in the North of Paris $(n=44)$, the South of Paris $(n=56)$, and Barcelona $(n=10)$.

\section{DNA extraction and amplification}

Total genomic DNA was isolated from toepads, the basal part of feathers or blood with the QIAamp DNA Micro Kit (Qiagen) following the manufacturer instructions for the blood and tissue samples. For the toe-pad samples the digestion volume was doubled, with the final concentration of $2-3 \mathrm{mg} / \mathrm{mL}$ for Proteinase $\mathrm{K}$ and $2 \cdot 10^{-2} \mathrm{mM}$ for dithiothreitol. For the phylogeographic study, a region of the mitochondrial gene cytochrome $b$ was amplified (797 bp). In the case of fresh tissues, the gene was amplified in one fragment whereas in the case of museum samples, short overlapping fragments (200-300 bp) were amplified with internal primers (table S2). The amplification protocols used are described in the supplementary material. For the population genetics study, the microsatellite loci described in Raisin et al. (2009) were used except for Peq07, Peq16 and Peq21 for which we had problems of amplification. A total 18 microsatellite loci were thus used. The amplification protocols used are also described in the supplementary material. Samples were genotyped on an Applied Biosystems 3130XL DNA sequencer. Genotypes were scored with GeneMapper 4.0 (Applied Biosystems) and checked manually. Living individuals were sexed using the PCRbased protocol of Griffiths et al. (1998), whereas for the museum specimens we relied on the information available on the specimen labels.

\section{Phylogeographic analyses}

Our data set was analyzed under the Bayesian inference and the maximum likelihood criteria. Psittacula echo, $P$. columboides, $P$. eupatria, P. longicauda, $P$. Alexandri, $P$. cyanocephala, $P$. himalayana, $P$. roseata, Tanygnathus sumatranus and Eclectus roratus were used as out-groups (table S1). The Bayesian inference was conducted with MRBAYES 3.1.2 (Ronquist and Huelsenbeck 2003). MrModelTest 2.3 (Nylander 2004) and PAUP* (Swofford 2003) were used to obtain the nucleotide substitution model best fitting the data, according to the AIC criterion (Akaike 1974). Uniform interval priors were selected for the parameters, except for base frequencies, which were assigned a Dirichlet prior (Huelsenbeck and Ronquist 2001). Two independent runs of four incrementally heated Metropolis-coupled MCMC chains were run for 10 million generations. Sampling was done every 1000 generations, yielding 20000 trees. The online version of AWTY (Nylander et al. 2008) was used to assess the convergence of the MCMC chains and to estimate the "burn-in" length. Maximum likelihood searches of the data set were conducted with RAxML v. 7.0.3 (Stamatakis 2006) using a GTR $+\Gamma+\mathrm{I}$ model and a random starting tree. Nodal support was estimated using 100 bootstrap replicates. The number of haplotypes, number of polymorphic sites, mean expected heterozygosity, mean pairwise distances between individuals, and mean nucleotide diversity were calculated with ARLEQUIN 3.5.2.1 (Excoffier and Lischer 2010). A second analysis was conducted on the mitochondrial sequences published by Jackson et al. (2015) as we noticed that there was a lot of missing data in these 
sequences and that this could have introduced a bias in their results. The analysis was conducted with the Bayesian inference approach described previously, with Psittacula echo used as outgroup, and the sequences with more than $30 \%$ of missing data were removed from the analysis.

\section{Population genetic analyses}

The presence of null alleles was assessed with FREENA (Chapuis and Estoup 2007). Sample sites with less than 15 individuals were excluded of the analysis to increase detection power. Mean number of alleles, Shannon's information index, observed heterozygosity, expected heterozygosity, unbiased expected heterozygosity, and fixation Index were assessed over all loci and for each sample site with GENEALEX 6.5 (Peakall and Smouse 2012). Deviation from Hardy-Weinberg equilibrium and linkage disequilibrium between pairs of loci were also tested for each sample site with GENEPOP 4.2.1 (Rousset 2008) using default parameter values. Pairwise $F_{S T}$ values were calculated between all populations with FREENA (Chapuis and Estoup 2007). The Bayesian clustering approach implemented in STRUCTURE 2.3.3 (Pritchard et al. 2000; Falush et al. 2003) was used to describe the genetic structure in the data set. Ten runs were performed for each value of $\mathrm{K}$ from 1 to 10 (burn-in period: $50.10^{3}, 150.10^{3}$ iterations). The admixture model and the assumption of correlated allele frequencies were chosen. The most likely number of clusters $(\mathrm{K})$ was inferred with the mean log-likelihood of the simulations for each value of $K$ and the value of deltaK calculated following Evanno et al. (2005). Convergence of the MCMC was assessed by checking the stabilization of the parameters $\alpha$ and $F$.

A complementary microsatellite data set published by Jackson et al. (2015) was also re-analyzed with STRUCTURE This data set contains microsatellite data for nine European populations for which we did not have samples (Amsterdam, Bonn,
Brussels, Dusseldorf, London, Rotterdam, Seville, The Hague and Wiesbaden), for Heidelberg, and for Asia and Africa. This data set was analyzed separately from ours as it contained data for only 10 of the loci we used and as there were peak shifts for some loci that could not be accounted for. Two STRUCTURE analyses were run with this data set. First individuals from both the native and invasive range were included. Three loci had a high proportion of missing data in the individuals of the native range (Peq 14: 84.8\%; Peq 15: 91.3\%, Peq 17: 88,0\%) and were excluded from this first analysis. In addition, all individuals with more than $20 \%$ of missing data were excluded. In the second analysis, the ten loci were kept but only the individuals from the invasive range were included. For this analysis also, all individuals with more than $20 \%$ of missing data were excluded. The parameters used for these two STRUCTURE analyses were similar to those we used for our own data set and all $\mathrm{K}$ values ranging from one to the number of sample locations were tested.

\section{Morphological data}

In order to study the morphology of Ringnecked parakeets, traditional morphological measurements as well as geometric morphometric data were used. For the traditional morphometric approach, six morphological measurements were recorded on all individuals. Upper mandible length (mm, two measurements), upper mandible width (mm) and upper mandible depth $(\mathrm{mm})$ and cranium length $(\mathrm{mm})$, were measured with a digital caliper (to nearest $0.1 \mathrm{~mm}$, figure S1a). Folded wing length $(\mathrm{mm})$ was measured on both wings with a metal ruler (to nearest 0.5 $\mathrm{mm}$ ) and averaged. To increase precision, all measurements were taken twice for live individuals and averaged. Log-shape ratios were used in order to allow the study of morphological variables independently of size (Mosimann and James 1979). Following this method, the overall size of 
each individual was defined as the mean of the log-transformed measurements. Each measurement was then standardized by subtracting the overall size of the individual to the log-transformed measured value.

Geometric morphometrics was used to describe more precisely the conformation of the beak (Zelditch et al. 2012). Pictures in lateral view of the beak of individuals were taken in standardized conditions. TPSDIG 2 (Rohlf 2010a) was used to digitize four landmarks (anatomical points) and 21 sliding semi-landmarks (non-homologous points) from these pictures in order to describe the beak shape (figure S1b, Gunz and Mitteroecker (2013)). All pictures were digitized by the same person and the repeatability of the digitization process was tested using a principal component analysis (PCA) on three repetitions taken on five specimens chosen randomly from the same sampling site. Variation was much lower within repetitions than between individuals, indicating the good repeatability of the digitization process (figure S2). A Generalized Procrustes superimposition (Rohlf and Slice 1990) of the points digitized for each individual was then performed using TPSRELW (Rohlf 2010b). With this method the sets of landmarks digitized for each individual are transformed by adjusting their position, rotation and scale, while conserving the shape they define (Adams et al. 2004). Sliding semi-landmarks are also allowed to slide along the curves they describe to match as well as possible the positions of the corresponding points in a reference specimen randomly chosen (Adams et al. 2004). The sliding method used was the minimization of the bending energy. The coordinates obtained after this step were those used for the analysis of shape. The size of the individuals was defined as the log-transformed centroid size (square root of the sum of square distances between each landmark and the gravity center of the object).

\section{Morphometric analyses}

Statistical analyses were done with $R$ 2.15.3 (R Core Team 2013) and using the libraries ade4 (Thioulouse et al. 1997), Ape (Paradis et al. 2004), Hotelling (Curran 2006) and Rmorph (Baylac 2012). All the analyses were done separately for the traditional measurements taken on the head and wings, and the for geometric morphometric data on the beak. In order to assess if there were morphological differences between groups of individuals (subspecies and European populations), both size and conformation of the individuals were compared.

Size- Analyses of covariance (ANCOVAs) were performed on the overall size (head/wing data set) and on the logtransformed centroid size (beak data set) with the group (subspecies or populations) as explicative variable. Sex and the interaction between group and sex were added as co-factors to control for sexual dimorphism and potential differences in sexual dimorphism between groups. When the interaction was not significant, it was removed from the model and the significance of the remaining factors was assessed using Type II Sum of Squares. Tuckey's HSD post hoc tests were used to test for pairwise differences between groups.

Conformation- PCAs were performed on the two data sets (head/wing and beak) and the principal component axes representing $95 \%$ of the total variance were kept as morphological variables for the later analyses. Before assessing if there was an effect of group on the conformation of individuals, we checked for differences in allometry between groups thanks to ANCOVAs performed for each morphological variable and for each data set with size, group, sex and all possible interactions between them as explicative factors. If the interaction between size and group was significant, the morphological variables were corrected for size by regressing size on it in order to avoid biases due to allometry. Then, the effect of 
group on the conformation of individuals was assessed with multivariate analyses of covariance (MANCOVAs) performed for each data set, with corrected morphological variables as response variables, and group as explicative variable. Sex and the interaction between group and sex were added as co-factors. When the interaction was not significant, it was removed from the model and the significance of the remaining factors was assessed using Type II Sum of Squares. Hotelling's T-squared post hoc tests were used to test for pairwise differences in conformation between groups. The threshold of acceptance of the null hypothesis was divided by the number of pairwise comparisons performed following the Bonferroni correction. Finally, neighbor-joining trees based on Euclidian distances between the centroid of each group were constructed to visualize the average differences in conformation between groups when the axes explaining $95 \%$ of the variability were considered all together.

\section{Results}

\section{Phylogeographic analyses}

The output of MRMODELTEST gave the $\mathrm{GTR}+\Gamma+\mathrm{I}$ model as the best fit for our data set. The trees obtained with the Bayesian inference and the maximum likelihood criteria were similar except for a few nodes. The analysis suggested that the African subspecies $P . \quad k$. krameri is paraphyletic and that the subspecies $P$. $k$. parvirostris and the two Asian subspecies derived from it. The sequence from the $P$. echo specimen fell in the clade formed by the $P$. krameri specimens, sister to the Asian clade, confirming the preliminary results obtained by Groombridge et al. (2004). The Asian subspecies were unresolved with the portion of cytochrome $b$ we used. The individuals from the European populations all fell in the Asian clade, except for one of the two samples from Marseille which had a haplotype similar to specimens of the $P$. k. krameri subspecies (Africa). The sample from Alger (Algeria) also fell in a clade composed of specimens of the $P . k$. krameri subspecies. We identified 13 haplotypes among the European individuals, with no haplotypes restricted to a single European population (figure 1). The number of haplotypes, number of polymorphic sites and nucleotide diversity were higher in the native range than in the invasive populations except for the subspecies $P$. $k$. parvirostris in which we only had two specimens, and for the population of Marseille in which we had two individuals belonging to different subspecies. However, the order of magnitude of these indices were comparable between the native and invasive range (Table S3). The analysis of the sequences published by Jackson et al. (2015) also showed a general distinction between the individuals from Asia and Africa but a few samples from Africa fell in the Asian clade (3 out of 38 ) and viceversa ( 3 out of 58 , figure $S 3$ ). Based on these data, no distinction appeared between the two African subspecies nor between the two Asian ones. Some haplotypes were even shared between the two Asian subspecies (figure S3). Concerning invasive populations, most haplotypes were similar or close to those found in Asia but a few haplotypes were similar to those found in Africa (4 samples out of 700, figure S3). Finally, two invasive individuals sampled in Mauritius were closer to the species Psittacula echo than to the other samples.

\section{Population genetics analyses}

Amplification of the 18 microsatellite loci was successful (98.3\% of loci successfully amplified over all samples) and all loci were polymorphic. No null alleles were detected. The genetic diversity ranged from 0.71 to 0.81 (table S4). The populations sampled did not significantly deviate from Hardy-Weinberg equilibrium 


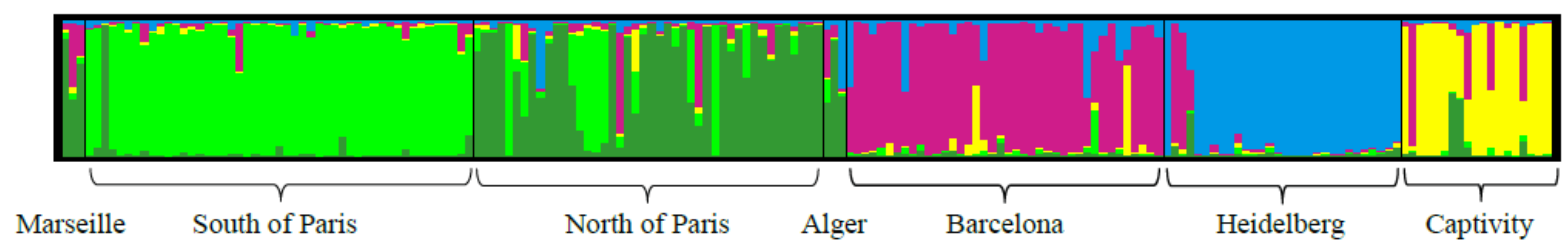

Fig. 2 Cluster assignments of individuals obtained with STRUCTURE for $K=5$. The results of the 10 runs were pooled together using CLuMPP (Jakobsson and Rosenberg 2007). Each vertical line represents a single individual and individuals are grouped by sampling site.

(HWE) nor presented linkage disequilibrium, except for Heidelberg and Barcelona (table S4) indicating possible structure in these populations. The genetic differentiation between populations $\left(\mathrm{F}_{\mathrm{ST}}\right)$ ranged between 0.039 and 0.13 (table S5). The log-likelihood of the simulations run with STRUCTURE increased sharply until $\mathrm{K}=5$ and then more slowly to reach a plateau (figure $\mathrm{S} 4 \mathrm{a}$ ). The delta $\mathrm{K}$ first peaked for $\mathrm{K}=2$ but there was a second more important peak at $\mathrm{K}=5$ (figure $\mathrm{S} 4 \mathrm{~b}$ ). For $\mathrm{K}=2$, there were two situations: either the individuals of the South of Paris were separated from all the others, or it was those from Spain and Germany. For $\mathrm{K}=5$, all the runs gave the same clustering of individuals. Each population was well distinguished except for the individuals of Marseille and Alger which were mainly grouped with those of the North of Paris. However, some individuals from each population had a mixed origin and a few individuals were assigned almost all the time to another cluster than the population in which they were caught as if they were first generation migrants (figure 2).

The STRUCTURE analysis of the microsatellite data set published by Jackson et al. (2015) with both native and invasive individuals gave a maximum value of delta $K$ for $K=2$, with the population of Heidelberg being separated from all the others (figure S5a). When we re-run this analysis excluding the individuals from Heidelberg, we also obtained a maximum value of delta $\mathrm{K}$ for $\mathrm{K}=2$. Roughly, the first group was composed of the individuals from London and Africa and the individuals from the other European populations and Asia formed the second group but there was some shared polymorphism between the Asian and African group (figure S5b). Similarly, the STRUCTURE analysis of this microsatellite data set when only invasive populations were considered gave a maximum value of delta $K$ for $K=2$, with the population of Heidelberg being separated from all the others (figure S5c). When we re-run this analysis excluding the individuals from Heidelberg, the delta $\mathrm{K}$ was also at its maximum value when $K=2$, with the population of London being separated from all the others (figure S5d). Finally, when we re-run this analysis excluding the individuals from Heidelberg and London, the delta $\mathrm{K}$ presented a first peak for $K=4$ and a second for $K=6$ (figure $\mathrm{S} 4 \mathrm{c})$. The cluster assignation was very noisy for the individuals caught in Brussel and Amsterdam when $\mathrm{K}$ was set to four whereas it was good when $\mathrm{K}$ was set to six. In addition, the log-likelihood of the simulations increased until $\mathrm{K}=6$ (figure $\mathrm{S} 4 \mathrm{c}$ ). We therefore considered that the most likely number of group was six. In this case, each population was well distinguished from the others except for Bonn, Dusseldorf and The Hague (figure S5e). The population of Rotterdam has two kinds of individuals with little admixture between them. The individuals caught in The Hague are genetically similar to one of the type of individuals from Rotterdam. Finally, the individuals caught in Bonn and Dusseldorf seem to have mixed origins similar to those of the individuals caught in Wiesbaden, Rotterdam and Seville (figure S5e). 


\section{Morphometric analyses}

Size- Group had a significant effect on size in the ANCOVAs performed on both data sets. Sex also had a significant effect on size (female were overall smaller and had a smaller beak than males) but the interactions between group and sex were not significant (table 2). Post hoc tests for the head/wing data set showed that there were significant differences in overall size between all groups except between the two African subspecies, the two Parisian populations and the Parisian populations and the Asian subspecies (table 3). The individuals of the African subspecies were smaller than the others (figure S6). For the beak data set, there were significant differences in size between all groups except between the two Asian subspecies and the two African subspecies (table 3). The individuals from the two African subspecies had a much smaller beak than those of the other species whereas the individuals from the two Parisian populations had a larger beak (figure S6).

Conformation- There were significant differences in allometry between groups for all morphological variables in the head/wing data set and for the first two variables in the beak data set (table S6). The morphological variables were therefore corrected for size. For both data sets, there was a significant effect of group on conformation. Sex also had a significant effect on conformation but not the interaction between group and sex (table 2).

For the head/wing data set, post hoc tests showed significant differences in conformation between all groups except between the two African subspecies, between $P . \quad k$. parvirostris and $P . \quad k$. manillensis and between $P$. $k$. parvirostris and the population of the North of Paris (table 4). Three main groups can be distinguished on the neighbor-joining tree: the Asian subspecies, the African subspecies and the Parisian populations (figure 3a). The morphospace defined by the first two axes of the PCA showed that for a similar size, the individuals from Paris had intermediate values of skull length, beak length and beak width but had longer wings and a less deep beak compared to the individuals of the African and Asian subspecies (figure 3a).

For the beak data set, there were significant differences in conformation between all groups except between the two African subspecies, the two Asian subspecies, the two Parisian populations, and between the populations of the North of Paris and Barcelona (table 4). Interestingly, there were also no significant differences between the African subspecies and the European populations. Two main groups can be distinguished on the neighbor-joining tree: the Asian subspecies and the African subspecies. The European populations lie in between these two groups (figure 3b). The morphospace defined by the first two axes of the PCA showed that for a similar size, the individuals from the European populations occupied intermediate positions between the African and Asian subspecies with the individuals from Barcelona being closer to the Asian group (figure 3b).

\section{Discussion}

\section{Origins of European populations of Ring-necked parakeets}

In the phylogeographic analysis based on our samples, the great majority of individuals from European populations fell in the Asian clade. This was also true when we re-analyzed the sequences published by Jackson et al. (2015). However, in this second analysis, the distinction between Asia and Africa was less clear as a few individuals from Africa fell in the Asian clade and vice-versa. Several reasons could explain this. First, it is possible that African and Asian populations still share some haplotypes. However, it is also possible that missing data, contaminations during amplification or confusions between samples introduced some errors in the data set. In any case, it seems that the 
Table 2: Results of the ANCOVAs on size and of the MANCOVAs on conformation.

\begin{tabular}{|c|c|c|c|c|}
\hline & Size & Df & F value & $P$ value \\
\hline \multirow{3}{*}{$\begin{array}{c}\text { Head/wing } \\
\text { data set }\end{array}$} & Sex:Group & 5,325 & 0.759 & 0.58 \\
\hline & Sex & 1,330 & 66.086 & $8.80 \mathrm{e}-15 *$ \\
\hline & Group & 5,330 & 204.652 & $<2.20 \mathrm{e}-16 *$ \\
\hline \multirow{4}{*}{$\begin{array}{c}\text { Beak } \\
\text { data set }\end{array}$} & Sex:Group & 5,345 & 0.135 & 0.98 \\
\hline & Sex & 1,350 & 13.596 & $2.62 \mathrm{e}-04 *$ \\
\hline & Group & 5,350 & 242.352 & $<2.20 \mathrm{e}-16 *$ \\
\hline & Conformation & Df & Approx F value & $\mathrm{P}$ value \\
\hline \multirow{3}{*}{$\begin{array}{c}\text { Head/wing } \\
\text { data set }\end{array}$} & Sex:Group & 5,325 & 0.678 & 0.88 \\
\hline & Sex & 1,330 & 2.971 & $1.22 \mathrm{e}-02 *$ \\
\hline & Group & 5,330 & 8.665 & $<2.20 \mathrm{e}-16 *$ \\
\hline \multirow{3}{*}{$\begin{array}{c}\text { Beak } \\
\text { data set }\end{array}$} & Sex:Group & 5,345 & 0.898 & 0.64 \\
\hline & Sex & 1,350 & 3.811 & $5.30 \mathrm{e}-04 *$ \\
\hline & Group & 5,350 & 6.592 & $<2.20 \mathrm{e}-16 *$ \\
\hline
\end{tabular}

Table 3: P-values of the post hoc tests for differences in size between pairs of group.

\begin{tabular}{|c|c|c|c|c|c|c|}
\hline Head/wing & P.k.krameri & P.k.parvirostris & P.k.borealis & P.k.manillensis & Paris (North) & Paris (South) \\
\hline P.k.parvirostris & 0.98 & & & & & \\
\hline P.k.borealis & $0.00 *$ & $0.00 *$ & & & & \\
\hline P.k.manillensis & $0.00 *$ & $0.00 *$ & $2.47 \mathrm{e}-03^{*}$ & & & \\
\hline Paris (North) & $0.00 *$ & $0.00 *$ & 1.00 & 0.22 & & \\
\hline Paris (South) & $0.00 *$ & $0.00^{*}$ & 0.20 & 0.89 & 0.65 & \\
\hline Barcelona & NA & NA & NA & NA & NA & NA \\
\hline Beak & P.k.krameri & P.k.parvirostris & P.k.borealis & P.k.manillensis & Paris (North) & Paris (South) \\
\hline P.k.parvirostris & 0.93 & & & & & \\
\hline P.k.borealis & $0.00 *$ & $0.00 *$ & & & & \\
\hline P.k.manillensis & $0.00 *$ & $0.00 *$ & 0.88 & & & \\
\hline Paris (North) & $0.00 *$ & $0.00 *$ & $0.00 *$ & $0.00 *$ & & \\
\hline Paris (South) & $0.00 *$ & $0.00 *$ & $0.00^{*}$ & $0.00 *$ & $0.00 *$ & \\
\hline Barcelona & $0.00 *$ & $0.00 *$ & $0.00 *$ & 0.00* & 0.00* & $0.00 *$ \\
\hline
\end{tabular}

Table 4: P-values of the post hoc tests for differences in conformation between pairs of group.

\begin{tabular}{|c|c|c|c|c|c|c|}
\hline Head/wing & P.k.krameri & P.k.parvirostris & P.k.borealis & P.k.manillensis & Paris (North) & Paris (South) \\
\hline P.k.parvirostris & $1.37 \mathrm{e}-02$ & & & & & \\
\hline P.k.borealis & $6.06 \mathrm{e}-10 *$ & $4.00 \mathrm{e}-05^{*}$ & & & & \\
\hline P.k.manillensis & $6.29 \mathrm{e}-08^{*}$ & $5.92 \mathrm{e}-03$ & $1.80 \mathrm{e}-07 *$ & & & \\
\hline Paris (North) & $1.72 \mathrm{e}-13^{*}$ & $1.15 \mathrm{e}-02$ & $2.22 \mathrm{e}-16^{*}$ & $6.66 \mathrm{e}-16^{*}$ & & \\
\hline Paris (South) & $3.32 \mathrm{e}-11 *$ & $4.00 \mathrm{e}-05^{*}$ & $0.00 *$ & $0.00 *$ & $1.28 \mathrm{e}-04 *$ & \\
\hline Barcelona & NA & NA & NA & NA & NA & NA \\
\hline Beak & P.k.krameri & P.k.parvirostris & P.k.borealis & P.k.manillensis & Paris (North) & Paris (South) \\
\hline P.k.parvirostris & $4.08 \mathrm{e}-02$ & & & & & \\
\hline P.k.borealis & $0.00 *$ & $1.11 \mathrm{e}-09^{*}$ & & & & \\
\hline P.k.manillensis & $0.00 *$ & $1.79 \mathrm{e}-07 *$ & 0.31 & & & \\
\hline Paris (North) & 0.45 & $6.13 \mathrm{e}-02$ & $6.00 e-15^{*}$ & $3.63 \mathrm{e}-12 *$ & & \\
\hline Paris (South) & 0.30 & $1.05 \mathrm{e}-05^{*}$ & $2.22 \mathrm{e}-16^{*}$ & $2.48 \mathrm{e}-13^{*}$ & $2.95 \mathrm{e}-02$ & \\
\hline Barcelona & $2.10 \mathrm{e}-02$ & 0.64 & $2.32 \mathrm{e}-04^{*}$ & $7.66 \mathrm{e}-04^{*}$ & $3.19 \mathrm{e}-03$ & $3.00 \mathrm{e}-04 *$ \\
\hline
\end{tabular}

* Indicates P-values under the adjusted significance threshold. 


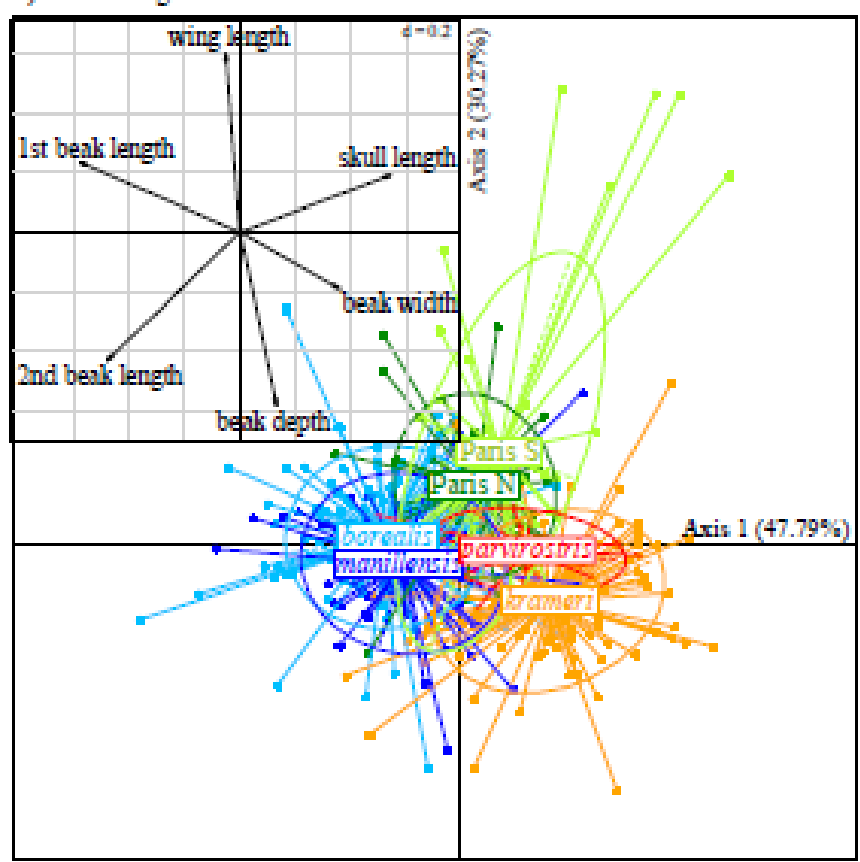

b) Beak data set

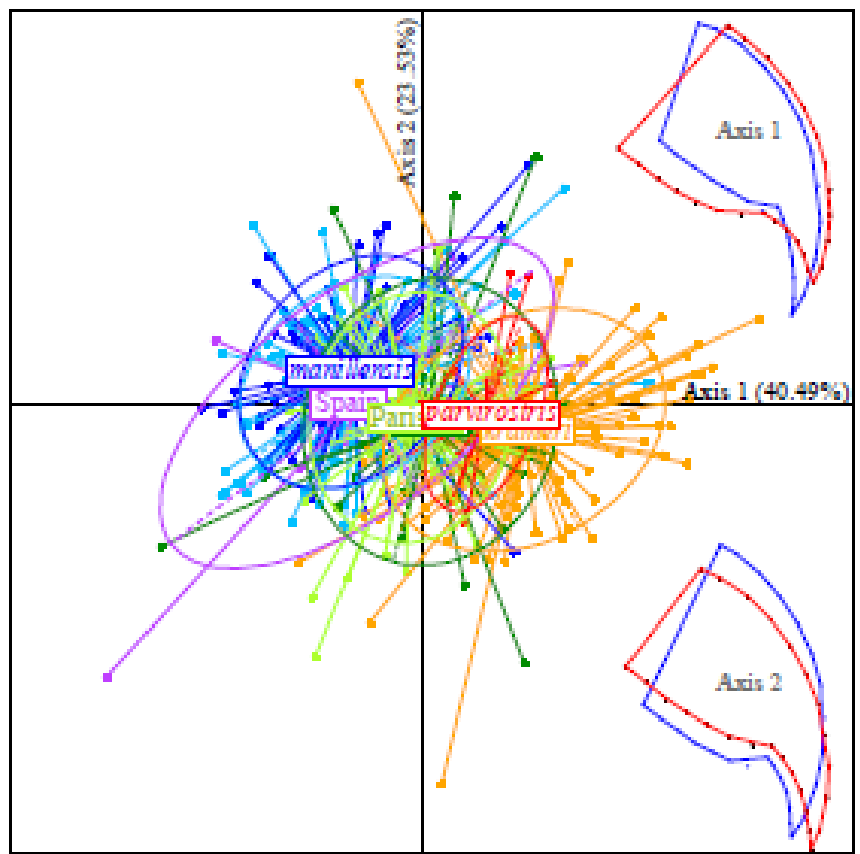

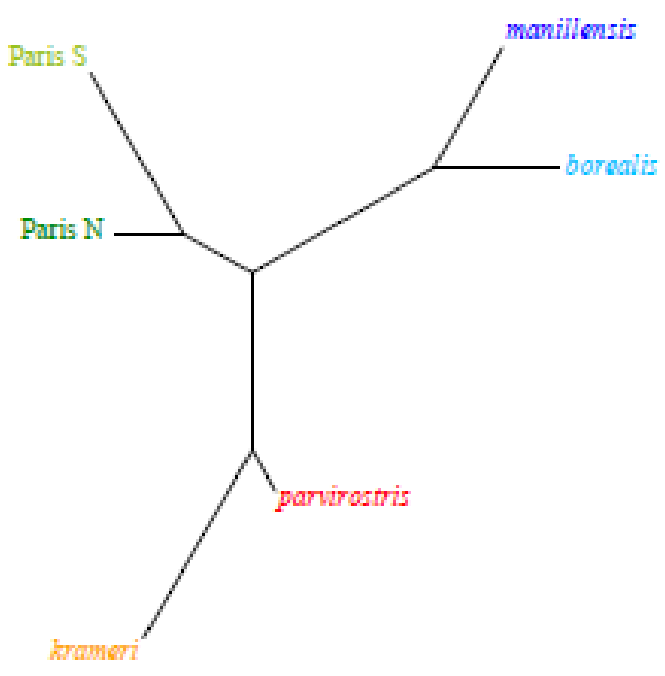

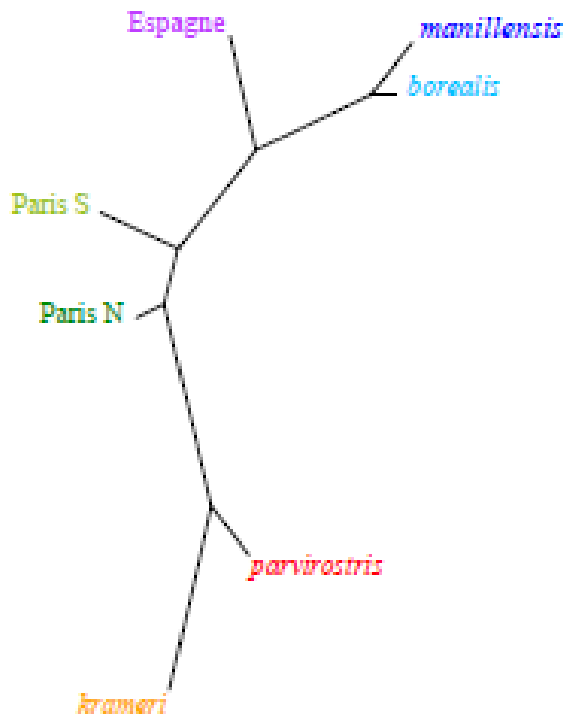

Fig. 3 Left: morphospaces defined by the two first axes of the PCA on conformation variables for a) the head/wing data set, and b) the beak data set. Right: neighbor-joining trees calculated with the Euclidian distance between the centroid of each group for a) the head/wing data set, and b) the beak data set. The correlation between variables and axes are represented for the PCA on traditional morphometric variables (head/wing data set). The extreme conformations associated to the axes are represented for the PCA on geometric morphometric variables (beak data set; red conformation: positive end of the axis; blue conformation: negative end of the axis). 
sources of the populations of Ring-necked parakeets established in Europe are located in great majority in the Indian subcontinent. Regarding the origin within India of the parakeets established in Europe, it is not possible to say with these analyses where they come from and whether there has been some admixture between the two Indian subspecies. Indeed, both the phylogeographic analyses based on our samples and on the sequences published by Jackson et al. (2015) do not distinguish these two subspecies. This might be caused by a lack of resolution in the cytochrome $b$ gene, which is rather conserved compared to other mitochondrial genes (Kerr 2011) but when the Asian subspecies are considered, there are 16 polymorphic sites in the portion of cytochrome $b$ we studied and eight different haplotypes. In addition, the sequences published by Jackson et al. (2015) also contained a portion of the control region. Jackson et al. (2015) were also unable to find distinctions between the haplotypes of the two Asian subspecies in their haplotype analysis although the number of individuals studied was very high. However, there was a lot of missing data in the sequences they published and this might have affected their results. It is thus possible that a sequencing of higher quality and possibly the addition of other markers would allow the distinction between the two Asian subspecies. This distinction was completely absent when they used microsatellite markers but here again, the high proportion of missing data especially for individuals from the native range might have prevented the detection of differences between the two Asian subspecies. However, we also did not find this distinction when we re-analyzed their data set after applying filters to minimize missing data. The possibility that the two subspecies are not genetically differentiated thus cannot be excluded, the current subspecies delimitation being based only on simple morphological traits and coloration patterns (del Hoyo et al.
1997). It would thus be interesting to reassess the current subspecies using a combination of molecular, morphologic and geographic data.

Our analysis of the microsatellite data set published by Jackson et al. (2015) suggested that some populations established in Europe might also have African origins. Indeed, after the exclusion of the populations of Heidelberg which was very different from the others, Asian and African populations were well differentiated although the signal suggested a limited shared ancestral polymorphism between this two groups. European populations were divided into two groups: the population of London which was closer to the African individuals whereas the other European populations were closer to Asian samples suggesting a possible part of African origin in the population of London. These results did not match with our mitochondrial data but Jackson et al. (2015) found a few African haplotypes in the European populations and there could have been an asymmetrical introgression between individuals from Asia and African in the UK. These results also only partly match with the results of the STRUCTURE analysis conducted by Jackson et al. (2015) on the same data set. Indeed, they found that every European population resulted in comparable proportion of a mix between Asian and African origins. However, there were a lot of missing data in this data set, especially for the samples from the native range and this might have introduced bias in their analysis. Conversely, our results match with the CITES data which shows that between 1981 and 2012 a higher proportion of Ring-necked parakeets from Africa were imported in the UK than from Asia, whereas the opposite is true for Spain and the Netherland. However, Belgium and Germany are in the same case as the UK and we did not detect African origins in these samples. These inconstancies might be due to the fact that trends in Ringnecked parakeet importations were 
different at the time European populations were founded, but as there are no CITES data on the trade of Ring-necked parakeets before 1981 it is not possible to know it.

In conclusion, it seems that most of the Ring-necked parakeets established in Europe come from Asia with a possibility that a lower proportion of individuals from Africa also established themselves. However, with the current mitochondrial data, it is not possible to say whether the Ring-necked parakeets established in Europe come from one or several regions in India and to identify these regions. Collecting fresh samples all over India and studying longer mitochondrial sequences as well as nuclear sequences thus seems necessary to further study the origins of European populations.

\section{Admixture in European populations of Ring-necked parakeets}

In general, our population genetics analysis shows well differentiated populations for each city. This suggests that invasive populations have experienced important bottlenecks and/or originate from distinct source populations. The genetic diversity we found in European populations for the cytochrome $b$ gene is smaller, but of the same order of magnitude, than the diversity found in Asia. This indicates a loss of genetic diversity after the introduction of the populations but not as important as one could expect in invasive populations which have experienced severe bottlenecks. In addition, there are several haplotypes represented in each European population. This suggests that each invasive population was founded by a large and genetically diverse population or by a mixture of different source populations. This is supported by our microsatellite data in which we also have, for each population, an important genetic diversity and the presence of some individuals with mixed or different origins. The genetic differentiation between populations is also important. In conclusion, it seems that European populations have been founded by different sources populations and it is possible that some populations received individuals from different sources.

We obtained similar results with the analysis of the microsatellite data set published by Jackson et al. (2015) once the populations of Heidelberg and London were removed. The reasons why the population of Heidelberg was found to be so different compared to the other populations in the analyses we did on the microsatellite data sat published by Jackson et al. (2015) could be diverse. First it is possible that this population is really different from all the others because it comes from a different source and that none of the samples from the native range come from this population. However, in our own data set, the samples from Heidelberg are not so differentiated from the others. It is therefore possible that there was a bias in the acquisition of microsatellite data for the Heidelberg samples in the data set published by Jackson et al. (2015). For example, there could have been a frameshift due to the use of a different sequencer, but without data on reference samples we cannot say if it is the case or not. It is also strange that this differentiation does not appear in the STRUCTURE analysis conducted by Jackson et al. (2015) but this could be due to the fact that they used a different threshold for the quality filtering. As we also collected samples from the population of Heidelberg, we decided to exclude this population in our analyses of the data set published by Jackson et al. (2015). Regarding the population of London which was found to be very differentiated compared to the other populations in the analysis of the European populations, this could be due to the fact that it is closer to the African samples and thus might have a partially different origin than the other European populations.

The general homogeneity at neutral genetic markers in each population suggests that each population had a different source, experienced founder 
effects and/or that founding populations were already homogeneous, possibly because of selection during the international trade process or a captivity period preceding release (Cabezas et al. 2013). However, the presence of individuals from different origin in the populations of Paris (North and South), Heidelberg, Rotterdam, and the presence of admixed individuals in these populations and in Marseille, Barcelona, Bonn and Dusseldorf suggest that individuals from different origins were introduced in these populations and that they interbred. The migration of individuals between the different European populations seems unlikely, except between the two Parisian populations, considering the distance existing between them and that most parrots are non-migratory (Forshaw 1989). However it is not totally impossible as some evidence of long-distance dispersal $(\sim 100 \mathrm{Km})$ were found in an invasive population of Monk parakeet which usually exhibit small dispersal distance in its native range (Da Silva et al. 2010).

Regarding the individuals from the captive stock, they also formed a homogeneous genetic group based on neutral markers. This is expected if we assume that the individuals raised in captivity have went through processes of artificial selection and inbreeding which would leave visible traces on their genetic diversity. There was only one population (Barcelona) that had individuals partly assigned to the same cluster as the one of the captive stock. There is therefore little evidence in our data set that captive stocks in Europe contribute to invasive populations. Finally, the presence of admixed individuals in the captive stock shows that individuals from different origins were also added to the captive stock and wild and captive populations thus seem to have been through quite similar demographic processes.

If European populations were indeed founded by several source populations or were joined later by migrants or escapees, admixture between individuals from different origin could partly explain the success of the Ringnecked parakeet in Europe. Indeed, multiple introductions of an invasive species and subsequent admixture within the introduction range has been shown to increase the genetic diversity and thus the adaptive potential of invasive populations (e.g. Facon et al. 2008; Kolbe et al. 2008; Verhoeven et al. 2011). However, as we did not find evidence of admixture in every European population, admixture cannot be the only factor explaining the invasive success of European populations. This conclusion was also reached in a recent study on the invasive Monk parakeets which showed that admixture was probably not a factor explaining the success of this species in Europe (Edelaar et al. 2015).

\section{Morphological adaptation}

Our morphological study showed that the Ring-necked parakeets in the European populations are different than in their source populations in the Indian subcontinent. Their overall conformation is different, with the individuals from Europe having, for a similar size, longer wings, a longer skull, and a beak wider but less deep and less long than the individuals from the Asian subspecies. The geometric morphometric study of the beak also showed that, when beaks of similar size are compared, individuals from Europe have a beak with a stockier conformation than individuals from Asia. In fact, according to the post hoc tests, they have a beak conformation that is not different from the beak conformation of the African subspecies. Finally, the size of their beak is different too, with individuals from European populations having bigger beaks than those from Asia. Our results differ from what was previously observed in the United Kingdom, where invasive Ringnecked parakeets were found to have a morphology closer to the Asian subspecies (especially $P . \quad k$. borealis) than to the African ones (Pithon and Dytham 2001; 
Butler 2003). However, in these two studies there were also differences between the invasive and native individuals.

The causes of this morphological divergence in invasive populations could be diverse. A plausible explanation is that these morphological changes are due to founder effect and genetic drift. Indeed, invasive species often go through important bottlenecks during foundation events, which would favor genetic drift. In addition, the founder population usually only represents a random sample of the genetic diversity found in the source population. Phenotypic changes due to bottlenecks and genetic drift alone have previously been reported (e.g. Runemark and Hansson 2010; O'Neill et al. 2012; Spurgin et al. 2014). However, we found that the genetic diversity was high in the European populations and genetic drift was therefore probably limited during the recent history of these populations. In addition, the fact that the three European populations we studied have changed in a similar way suggest that random processes alone are unlikely to explain this divergence. Indeed, although there are significant differences in general conformation, beak conformation and beak size between some of the European populations, they appear closer in the morphospace we defined than they are to the Asian subspecies. This is especially true for the two Parisian populations which experience very similar environmental conditions, which were founded independently, and seem to have limited contact according to the low number of migrants we detected. It is therefore possible that the morphological divergence we observed is due to a convergent adaptation to environmental conditions. The fact that invasive individuals have longer wings could indicate that the vegetation is less dense in their European habitat than in their native one. It could also indicate that individuals have to travel longer distances, for example between roosting sites and feeding or nesting sites, in Europe than in their native range. Finally, the bigger and stronger beaks of the invasive individuals could be adapted to the consumption of harder food items in Europe than in the native range. Indeed, soft fruits and blossoms are only available during spring and summer in Europe whether it is available all-year round in the tropics. However, these are only suppositions and detailed information on the environmental conditions found in the native and invasive range would be needed to investigate the drivers of the morphological changes we observed. Alternatively, these morphological changes could be the result of selection happening during the transfer of wild individuals to Europe as strong mortality (and thus strong selective forces) is registered for parrots during the international trade process (over 75\%; Cabezas et al. (2013). These morphological changes could also reflect natural or artificial selection during captivity as pet birds can also be raised in captivity for several generations before being sold (Carrete and Tella 2008). The morphological changes we observed would then reflect adaptation to transfer and/or captivity rather than adaptation to European environment. In support to this hypothesis, Cabezas et al. (2013) showed that wild caught parakeet have a stronger reaction to acute stress (longer expression of corticosterone) than captive bred animals, suggesting either natural selection of individuals better able to respond to acute stress during transfer of wild animals or adaptation to acute stress in captive bred animals via natural or artificial selection. However, it seems most likely that selection caused by captivity would affect the physiology and immune system of the individuals than their morphology, especially the morphology of the wings as flight possibilities are probably very restrained during captivity.

If these morphological changes are due to convergent adaptation, they could be driven either by phenotypic plasticity or by natural selection. The important genetic 
diversity we observed in the European populations suggests that the genetic diversity could also have been high at the time of introduction which would have favored adaptation by natural selection on standing variation in these populations. In addition, we found evidence for admixture in some European populations which might also have favored adaptation via natural selection thanks to the emergence of new genetic associations. It is thus possible that natural selection acted on European populations and induced rapid phenotypic changes (in about 10 generations based on a generation time of 5.6 years (Jackson et al. 2015)). Examples of such rapid adaptation have already been described during colonization processes although the mechanisms involved are not always clear (Conant 1988; Losos et al. 1997; Reznick et al. 1997; Kristjánsson et al. 2002; Kristjánsson et al. 2004; Phillips et al. 2006; Amiot et al. 2007). In addition, a recent study on invasive Monk parakeets also suggests that there might be a convergent adaptation in the invasive populations studied (Edelaar et al. 2015). In the case of the Ring-necked parakeet, the morphological differences still existing between populations could result from adaptation to slightly different local conditions or to mixed influence of admixture, genetic drift, artificial selection and natural selection. Conducting further studies, such as common garden experiments or genomic approaches, would be interesting to investigate the role of phenotypic plasticity, selection and random processes in this morphological divergence.

\section{Acknowledgements}

We thank the LabEx BcDiv which financed our genetic analyses, the Observatoire de la Biodiversité Urbaine (Département Seine-Saint-Denis) and the Conseil Général du Département des Hauts-de-Seine which financed the captures of Ring-necked parakeets, the British Natural History Museum and the Muséum National d'Histoire Naturelle for giving us access to their collection of Ringnecked parakeets, the Muséum National d'Histoire Naturelle, the Naturhistoriska Riksmuseet, and Professor Michael Wink (Institute of Pharmacy and Molecular Biotechnology, Heidelberg University) for the samples they lent us. Finally, we thank the molecular systematic platform (SSM) of the Muséum National d'Histoire Naturelle, its staff, and particularly Josie Lambourdière. This study contributes to the reflections conducted by the European network on invasive parakeets: Parrotnet. 


\section{References}

Adachi T, Ishikawa A, Mori S, et al (2012) Shifts in morphology and diet of non-native sticklebacks introduced into Japanese crater lakes. Ecol Evol 2:1083-98.

Adams DC, Rohlf FJ, Slice DE (2004) Geometric morphometrics: Ten years of progress following the "revolution." Ital J Zool 71:5-16.

Akaike H (1974) A new look at the statistical model identification. IEEE Trans Automat Contr 19:716-723.

Amiot C, Lorvelec O, Mandon-Dalger I, et al (2007) Rapid morphological divergence of introduced Red-whiskered Bulbuls Pycnonotus jocosus in contrasting environments. Ibis 149:482-489.

Baylac M (2012) Rmorph: A "R" Geometric Multivariate Morphometrics Library; baylac@mnhn.fr.

Boag PT, Grant PR (1981) Intense natural selection in a population of Darwin's finches (Geospizinae) in the Galapagos. Science 214:82-85.

Braun M (2009) Die Bestandssituation des Halsbandsittichs Psittacula krameri in der RheinNeckar-Region (Baden-Württemberg, Rheinland-Pfalz, Hessen), 1962-2008, im Kontext der gesamteuropäischen Verbreitung. Vogelwelt 130:77-89.

Butler CJ (2003) Population Biology of the Introduced Rose-ringed Parakeet Psittacula krameri in the UK Thesis submitted by. University of Oxford

Cabezas S, Carrete M, Tella JL, et al (2013) Differences in acute stress responses between wild-caught and captive-bred birds: A physiological mechanism contributing to current avian invasions? Biol Invasions 15:521-527.

Carrete M, Tella J (2008) Wild-bird trade and exotic invasions: a new link of conservation concern? Front Ecol Environ 6:207-211.

Chapuis M-P, Estoup A (2007) Microsatellite null alleles and estimation of population differentiation. Mol Biol Evol 24:621-31.

CITES (2015) The CITES Trade Database. http://trade.cites.org/.

Clergeau P, Vergnes A (2011) Bird feeders may sustain feral Rose-ringed parakeets Psittacula krameri in temperate Europe. Wildlife Biol 17:248-252.

Conant S (1988) Geographic variation in the Laysan Finch (Telespyza cantans). Evol Ecol 2:270-282.

Curran JM (2006) R Package "Hotelling." 
Da Silva AG, Eberhard JR, Wright TF, et al (2010) Genetic evidence for high propagule pressure and long-distance dispersal in monk parakeet (Myiopsitta monachus) invasive populations. Mol Ecol 19:3336-3350.

Del Hoyo J, Elliott A, Sargatal J (eds) (1997) Handbook of the Birds of the World (Volume 4): Sandgrouse to Cuckoos. Lynx Edicions

Desrochers A (2010) Morphological response of songbirds to 100 years of landscape change in North America. Ecology 91:1577-82.

Dlugosch KM, Parker IM (2008) Founding events in species invasions: genetic variation, adaptive evolution, and the role of multiple introductions. Mol Ecol 17:431-49.

Edelaar P, Roques S, Hobson EA., et al (2015) Shared genetic diversity across the global invasive range of the monk parakeet suggests a common restricted geographic origin and the possibility of convergent selection. Mol Ecol. 24:2164-76.

Evanno G, Regnaut S, Goudet J (2005) Detecting the number of clusters of individuals using the software STRUCTURE: a simulation study. Mol Ecol 14:2611-20.

Excoffier L, Lischer HEL (2010) Arlequin suite ver 3.5: A new series of programs to perform population genetics analyses under Linux and Windows. Mol Ecol Resour 10:564-567.

Facon B, Pointier J-P, Jarne P, et al (2008) High genetic variance in life-history strategies within invasive populations by way of multiple introductions. Curr Biol 18:363-7.

Falush D, Stephens M, Pritchard JK (2003) Inference of population structure using multilocus genotype data: linked loci and correlated allele frequencies. Genetics 164:1567-87.

Forshaw JM (1989) Parrots of the World. Landsdowe, Willoughby, Australia

Griffiths R, Double M, Orr K, Dawson R (1998) A DNA test to sex most birds. Mol Ecol 7:1071-75.

Groombridge JJ, Jones CG, Nichols RA, et al (2004) Molecular phylogeny and morphological change in the Psittacula parakeets. Mol Phylogenet Evol 31:96-108.

Gunz P, Mitteroecker P (2013) Semilandmarks: a method for quantifying curves and surfaces. Hystrix, Ital J Mammal. doi: 10.4404/hystrix-24.1-6292

Herrel A, Podos J, Huber SK, Hendry AP (2005) Evolution of bite force in Darwin's finches: a key role for head width. J Evol Biol 18:669-75.

Huelsenbeck JP, Ronquist F (2001) MRBAYES: Bayesian inference of phylogenetic trees. Bioinformatics 17:754-5.

Jackson H, Strubbe D, Tollington S, et al (2015) Ancestral origins and invasion pathways in a globally invasive bird correlate with climate and influences from bird trade. Mol Ecol 24:4269-4285. 
Jakobsson M, Rosenberg NA (2007) CLUMPP: a cluster matching and permutation program for dealing with label switching and multimodality in analysis of population structure. Bioinformatics 23:1801-6.

Kerr KCR (2011) Searching for evidence of selection in avian DNA barcodes. Mol Ecol Resour 11:1045-1055.

Kolbe JJ, Larson A, Losos JB, de Queiroz K (2008) Admixture determines genetic diversity and population differentiation in the biological invasion of a lizard species. Biol Lett 4:434-7.

Kooyers NJ, Olsen KM (2012) Rapid evolution of an adaptive cyanogenesis cline in introduced North American white clover (Trifolium repens L.). Mol Ecol 21:2455-68.

Kristjánsson BK, Skúlason S, Noakes DLG (2004) Unusual number of pectoral fin rays in an Icelandic population of threespine stickleback (Gasterosteus aculeatus) recently isolated in freshwater. Evol Ecol 18:379-384.

Kristjánsson BK, Skúlason S, Noakes DLG (2002) Rapid divergence in a recently isolated population of threespine stickleback (Gasterosteus aculeatus L .). Evol Ecol Res 4:659672.

Lee CE (2002) Evolutionary genetics of invasive species. Trends Ecol Evol 5347:9-11.

Lee CE, Gelembiuk GW (2008) Evolutionary origins of invasive populations. Evol Appl $1: 427-448$.

Leisler B, Winkler H (1985) Ecomorphology. Curr Ornithol 2:155-186.

Losos JB, Warheit KI, Schoener TW (1997) Adaptive differentiation following experimental island colonization in Anolis lizards. Nature 387:70-73.

Morgan DHW (1993) Feral Rose-ringed parakeets in Britain. Br Birds 86:561-564.

Mosimann J, James F (1979) New statistical methods for allometry with application to Florida red-winged blackbirds. Evolution 33:444-459.

Nylander JAA (2004) MrModeltest v2. Program distributed by the author. Evolutionary Biology Centre, Uppsala University.

Nylander JAA, Wilgenbusch JC, Warren DL, Swofford DL (2008) AWTY (are we there yet?): a system for graphical exploration of MCMC convergence in Bayesian phylogenetics. Bioinformatics 24:581-3.

O'Neill E, Beard K, Pfrender M (2012) Cast adrift on an island: introduced populations experience an altered balance between selection and drift. Biol Lett 2012-2015.

Paradis E, Claude J, Strimmer K (2004) APE: Analyses of Phylogenetics and Evolution in R language. Bioinformatics 20:289-290. 
Parr M, Juniper T (2010) A guide of the Parrots of the world. Bloomsbury Publishing

Peakall R, Smouse PE (2012) GenAlEx 6.5: genetic analysis in Excel. Population genetic software for teaching and research-an update. Bioinformatics 28:2537-9.

Phillips BL, Brown GP, Webb JK, Shine R (2006) Invasion and the evolution of speed in toads. Nature 439:803.

Pithon JA, Dytham C (2001) Determination of the origin of British feral Rose-ringed Parakeets. Br Birds 94:74-79.

Pritchard JK, Stephens M, Donnelly P (2000) Inference of population structure using multilocus genotype data. Genetics 155:945-59.

R Core Team (2013) R: A language and environment for statistical computing. R Foundation for Statistical Computing, Vienna, Austria.

Raisin C, Dawson DA, Greenwood AG, et al (2009) Characterization of Mauritius parakeet (Psittacula eques) microsatellite loci and their cross-utility in other parrots (Psittacidae, Aves). Mol Ecol Resour 9:1231-35.

Reznick D, Shaw F, Rodd F, Shaw R (1997) Evaluation of the Rate of Evolution in Natural Populations of Guppies (Poecilia reticulata). Science 275:1934-7.

Rohlf FJ (2010a) TPSDIG, version 2.16. Stony Brook, NY: SUNY: Department of Ecology and Evolution.

Rohlf FJ (2010b) TPSRELW, version 1.49. Stony Brook, NY: SUNY: Department of Ecology and Evolution.

Rohlf FJ, Slice D (1990) Extensions of the Procrustes Method for the Optimal Superimposition of Landmarks. Syst Zool 39:40.

Rollins LA, Richardson MF, Shine R (2015) A genetic perspective on rapid evolution in cane toads ( Rhinella marina ). Mol Ecol 24:2264-2276.

Ronquist F, Huelsenbeck JP (2003) MrBayes 3: Bayesian phylogenetic inference under mixed models. Bioinformatics 19:1572-1574.

Rousset F (2008) genepop'007: a complete re-implementation of the genepop software for Windows and Linux. Mol Ecol Resour 8:103-6.

Runemark A, Hansson B (2010) Island biology and morphological divergence of the Skyros wall lizard Podarcis gaigeae: a combined role for local selection and genetic drift on color morph. BMC Evol Biol 10:269.

Shwartz A, Strubbe D, Butler CJ, et al (2009) The effect of enemy-release and climate conditions on invasive birds: a regional test using the rose-ringed parakeet ( Psittacula krameri ) as a case study. Divers Distrib 15:310-318. 
Spurgin LG, Illera JC, Jorgensen TH, et al (2014) Genetic and phenotypic divergence in an island bird: isolation by distance, by colonization or by adaptation? Mol Ecol 23:102839.

Stamatakis A (2006) RAxML-VI-HPC: maximum likelihood-based phylogenetic analyses with thousands of taxa and mixed models. Bioinformatics 22:2688-90.

Stockwell CA, Weeks SC (1999) Translocations and rapid evolutionary responses in recently established populations of western mosquitofish (Gambusia affinis). Anim Conserv 2:103-110.

Strubbe D, Jackson H, Groombridge J, Matthysen E (2015) Invasion success of a global avian invader is explained by within-taxon niche structure and association with humans in the native range. Divers Distrib 21:675-685.

Strubbe D, Matthysen E (2009) Establishment success of invasive ring-necked and monk parakeets in Europe. J Biogeogr 36:2264-2278.

Swofford DL (2003) PAUP*. Phylogenetic Analysis Using Parsimony (*and Other Methods). Sinauer Associates, Sunderland, Massachusetts.

Thioulouse J, Chessel D, Dolédec S, Olivier JM (1997) ADE-4: a multivariate analysis and graphical display software. Stat Comput 7:75-83.

Verhoeven KJF, Macel M, Wolfe LM, Biere A (2011) Population admixture, biological invasions and the balance between local adaptation and inbreeding depression. Proc $\mathrm{R}$ Soc B Biol Sci 278:2-8.

Yonekura R, Kawamura K, Uchii K (2007) A peculiar relationship between genetic diversity and adaptability in invasive exotic species: bluegill sunfish as a model species. Ecol Res 22:911-919.

Zelditch ML, Swiderski DL, Sheets HD (2012) Geometric morphometrics for biologists: a primer. Academic Press 


\section{Supplementary Material}

\section{Amplification Protocols}

Cytochrome b:

Reagent quantities for amplification in a single fragment: $13.94 \mu \mathrm{L}$ of Milli-Q water, $2 \mu \mathrm{L}$ of polymerase buffer 10x (Qiagen), $1.5 \mu \mathrm{L}$ of $\mathrm{MgCl}_{2}$ (Qiagen, $25 \mathrm{mM}$ ), $1 \mu \mathrm{L}$ of Dimethyl sulfoxide (DMSO), $0.8 \mu \mathrm{L}$ of dNTPs mix $(1.7 \mathrm{mM}$ each), $0.32 \mu \mathrm{L}$ of each primer $(10 \mu \mathrm{M})$, $0.12 \mu \mathrm{L}$ of DNA polymerase (Qiagen, Taq 5 units $/ \mu \mathrm{L}$ ). Cycling conditions: $94^{\circ} \mathrm{C}, 5 \mathrm{~min}$.; $\left(94^{\circ} \mathrm{C}, 40 \mathrm{sec}\right.$.; $57^{\circ} \mathrm{C}, 40 \mathrm{sec}$; $72^{\circ} \mathrm{C}, 60 \mathrm{sec}$.) x 40 cycles; $72^{\circ} \mathrm{C}, 5 \mathrm{~min}$.

For the amplification of short fragments, illustra ${ }^{\mathrm{TM}}$ Hot Start Mixes (GE Healthcare) were used with the following reagent quantities: $19 \mu \mathrm{l}$ of Milli-Q water, $1 \mu \mathrm{L}$ of $\mathrm{MgCl}_{2}$ (Qiagen, $25 \mathrm{mM}), 1 \mu \mathrm{L}$ of each primer $(10 \mu \mathrm{M})$. Cycling conditions: $94^{\circ} \mathrm{C}, 5 \mathrm{~min}$.; $\left(94^{\circ} \mathrm{C}, 40\right.$ sec.; $61^{\circ} \mathrm{C}, 40 \mathrm{sec}$; $72^{\circ} \mathrm{C}, 60$ sec.) x 4 cycles; $\left(94^{\circ} \mathrm{C}, 40 \mathrm{sec}\right.$; $59^{\circ} \mathrm{C}, 40 \mathrm{sec}$; $72^{\circ} \mathrm{C}, 60$ sec. $) \times$ cycles; $\left(94^{\circ} \mathrm{C}, 40 \mathrm{sec} . ; 57^{\circ} \mathrm{C}, 40 \mathrm{sec}\right.$; $72^{\circ} \mathrm{C}, 60 \mathrm{sec}$. $)$ x 32 cycles; $72^{\circ} \mathrm{C}, 5 \mathrm{~min}$.

Microsatellites loci:

Microsatellite loci were amplified in three multiplex and tagged with fluorescent forward primers (dyes: 6-FAM, VIC, NED, PET; Applied Biosystems). PCR amplifications were done using the following reagent quantities: $1.25 \mu \mathrm{L}$ of the primer mix $(1 \mu \mathrm{M}$ of each primer and TE buffer), $4 \mu \mathrm{L}$ of RNase-free water (Qiagen), $6.25 \mu \mathrm{L}$ of $2 x$ Type-it Multiplex PCR Master Mix (Qiagen) in a final volume of $11.5 \mu \mathrm{L}$. Cycling conditions: $95^{\circ} \mathrm{C}, 5 \mathrm{~min} . ;\left(95^{\circ} \mathrm{C}, 30 \mathrm{sec} . ; 57^{\circ} \mathrm{C}\right.$, $90 \mathrm{sec}$.; $72^{\circ} \mathrm{C}, 30 \mathrm{sec}$.) $\times 25$ cycles; $60^{\circ} \mathrm{C}, 30 \mathrm{~min}$.

\section{Supplementary tables}

Table S1: details of the specimens used in the phylogeographic analysis.

\begin{tabular}{|c|c|c|c|c|c|}
\hline Species & Subspecies & Country & Locality & ID Number & Genbank \\
\hline P. krameri & manillensis & Sri Lanka & Ratnapura & MNHN 1928.1834 & KU609567 \\
\hline P. krameri & manillensis & NA & NA & NA & GQ996517 \\
\hline P. krameri & manillensis & NA & NA & NA & AY220112 \\
\hline P. krameri & manillensis & NA & NA & NA & AY220111 \\
\hline P. krameri & manillensis & NA & NA & NA & AY220110 \\
\hline P. krameri & borealis & India & Madhya Pradesh - Mandla & MNHN 1939.247 & KU609565 \\
\hline P. krameri & borealis & India & Madhya Pradesh & MNHN 2005.1910 & KU609566 \\
\hline P. krameri & borealis & Pakistan & NA & NA & KC876658 \\
\hline P. krameri & borealis & Pakistan & NA & NA & KC876653 \\
\hline P. krameri & borealis & Pakistan & NA & NA & KC876663 \\
\hline P. krameri & borealis & NA & NA & NA & AY220116 \\
\hline P. krameri & parvirostris & Eritrea & Cheren & NRM 571654 & KU609561 \\
\hline P. krameri & parvirostris & Ethiopia & Tacazzé & NRM 571659 & KU609562 \\
\hline P. krameri & krameri & NA & NA & NA & AY220114 \\
\hline P. krameri & krameri & NA & NA & NA & AY220117 \\
\hline P. krameri & krameri & Mali & Bandiagara - Gouandaka & MNHN 1933.1523 & KU609557 \\
\hline P. krameri & krameri & Mali & Koulikoro - Koulikoro & MNHN 1962.3565 & KU609558 \\
\hline
\end{tabular}




\begin{tabular}{|c|c|c|c|c|c|}
\hline Species & Subspecies & Country & Locality & ID Number & Genbank \\
\hline P. krameri & krameri & Tchad & Baguirmi - East of Ndjamena & MNHN 1936.1099 & KU609563 \\
\hline P. krameri & krameri & Tchad & West Ennedi & MNHN 1959.27 & KU609564 \\
\hline P. krameri & krameri & Cameroun & Logone-et-Chari - Waza & MNHN 1967.715 & KU609559 \\
\hline P. krameri & krameri & Cameroun & NA & MNHN 2000.952 & KU609560 \\
\hline P. krameri & NA & Algeria & Alger & ALG Ager1 & KU609544 \\
\hline P. krameri & NA & France & Marseille & ALG M1 & KU609549 \\
\hline P. krameri & NA & France & Marseille & ALG M3 & KU609545 \\
\hline P. krameri & NA & France & Villepinte & ALG V1 & KU609550 \\
\hline P. krameri & NA & France & Villepinte & ALG V2 & KU609550 \\
\hline P. krameri & NA & France & Villepinte & ALG V38 & KU609551 \\
\hline P. krameri & NA & France & Villepinte & ALG V40 & KU609551 \\
\hline P. krameri & NA & France & Villepinte & ALG V41 & KU609552 \\
\hline P. krameri & NA & France & Antony & ALG A25 & KU609547 \\
\hline P. krameri & NA & France & Antony & ALG A26 & KU609548 \\
\hline P. krameri & NA & France & Antony & ALG A27 & KU609548 \\
\hline P. krameri & NA & France & Antony & ALG A28 & KU609548 \\
\hline P. krameri & NA & France & Chatenay-Malabry & ALG C1 & KU609547 \\
\hline P. krameri & NA & France & Captivity & ALG DB1 & KU609546 \\
\hline P. krameri & NA & France & Captivity & ALG DB2 & KU609549 \\
\hline P. krameri & NA & France & Captivity & ALG DB3 & KU609549 \\
\hline P. krameri & NA & France & Captivity & ALG DB4 & KU609549 \\
\hline P. krameri & NA & France & Captivity & ALG DB5 & KU609549 \\
\hline P. krameri & NA & France & Captivity & ALG DB7 & KU609549 \\
\hline P. krameri & NA & France & Captivity & ALG DB8 & KU609549 \\
\hline P. krameri & NA & France & Captivity & ALG DB9 & KU609549 \\
\hline P. krameri & NA & France & Captivity & ALG DB10 & KU609546 \\
\hline P. krameri & NA & Germany & Heidelberg & B 48014 & KU609553 \\
\hline P. krameri & NA & Germany & Heidelberg & B 48015 & KU609554 \\
\hline P. krameri & NA & Germany & Heidelberg & B 48016 & KU609555 \\
\hline P. krameri & NA & Germany & Heidelberg & B 48018 & KU609555 \\
\hline P. krameri & NA & Germany & Heidelberg & В 52997 & KU609555 \\
\hline P. krameri & NA & Germany & Heidelberg & В 52998 & KU609555 \\
\hline P. krameri & NA & Germany & Heidelberg & В 53000 & KU609555 \\
\hline P. krameri & NA & Germany & Heidelberg & В 53006 & KU609555 \\
\hline P. krameri & NA & Germany & Heidelberg & В 53007 & KU609555 \\
\hline P. krameri & NA & Spain & Barcelona & S Esp95 & KU609556 \\
\hline P. krameri & NA & Spain & Barcelona & S M4231 & KU609547 \\
\hline P. krameri & NA & Spain & Barcelona & S 4138695 & KU609547 \\
\hline P. krameri & NA & Spain & Barcelona & S M4234 & KU609547 \\
\hline P. krameri & NA & Spain & Barcelona & S 4134849 & KU609547 \\
\hline P. krameri & NA & Spain & Barcelona & S 4138661 & KU609547 \\
\hline P. krameri & NA & Spain & Barcelona & S 4138694 & KU609547 \\
\hline P. echo & NA & NA & NA & NA & AY220113 \\
\hline
\end{tabular}




\begin{tabular}{|c|c|c|c|c|c|}
\hline Species & Subspecies & Country & Locality & ID Number & Genbank \\
\hline P. columboides & NA & NA & NA & NA & AY220108 \\
\hline P. eupatria & NA & NA & NA & NA & AY220115 \\
\hline P. longicauda & NA & NA & NA & NA & GQ996509 \\
\hline P. Alexandri & NA & NA & NA & NA & AY220105 \\
\hline P. cyanocephala & NA & NA & NA & NA & AY220109 \\
\hline P. himalayana & NA & NA & NA & NA & KJ456436 \\
\hline P. roseata & NA & NA & NA & NA & AY220107 \\
\hline $\begin{array}{l}\text { Tanygnathus } \\
\text { sumatranus }\end{array}$ & NA & NA & NA & NA & AB177972 \\
\hline Eclectus roratus & NA & NA & NA & NA & AY220101 \\
\hline
\end{tabular}

Table S2: Primers used to amplify fragments of the cytochrome $b$ gene.

\begin{tabular}{lllll} 
Gene & Primer F & & Primer R & \\
\hline Cytb (single fragment) & ALG-L14841 & CCATCCAACATCTCAGCATGATGAAA & ALG-cytb-R813 & GAATAGGTTGGCGGCGAGTGTTCAGA \\
Cytb (1st fragment) & ALG-L14841 & CCATCCAACATCTCAGCATGATGAAA & ALG-cytb-R221 & GCCTCATGGTAAGACATAGCCAACGA \\
Cytb (2nd fragment) & ALG-cytb-F173 & CCTGAAACACAGGAATCATCCTCCTA & ALG-cytb-R422 & TGATTCGTGGAGAAAGGTTAGGTGGA \\
Cytb (3rd fragment) & ALG-cytb-F356 & CCACCTTAACACGATTCTTCGCCCTA & ALG-cytb-R605 & AGTTGTTAGGGGGTTTGCTGGGGTGA \\
Cytb (4th fragment) & ALG-cytb-F551 & CCCTCACCACCCTTGCCCTATTCTCA & ALG-cytb-R813 & GAATAGGTTGGCGGCGAGTGTTCAGA \\
\hline
\end{tabular}

Table S3: Genetic diversity for the cytochrome $b$ gene.

\begin{tabular}{|c|c|c|c|c|c|c|}
\hline & Nind & Nhaplo & Nsites & ExpHe & Pairwise Distance & Nucleotide Diversity \\
\hline P. k. manillensis & 5 & 5 & 10 & $0.42(+/-6.33 e-02)$ & $4.20(+/-2.50)$ & $5.27 \mathrm{e}-03(+/-3.67 \mathrm{e}-03)$ \\
\hline P. k. borealis & 6 & 3 & 12 & $0.58(+/-7.70 \mathrm{e}-02)$ & $6.93(+/-3.80)$ & $8.70 \mathrm{e}-03(+/-5.51 \mathrm{e}-03)$ \\
\hline P. k. parvirostris & 2 & 1 & . & . & . & . \\
\hline P. k. krameri & 8 & 6 & 17 & $0.42(+/-9.88 \mathrm{e}-02)$ & $7.18(+/-3.77)$ & $9.01 \mathrm{e}-03(+/-5.38 \mathrm{e}-03)$ \\
\hline Alger & 1 & 1 & . & . & . & . \\
\hline Marseille & 2 & 2 & 23 & $1.00(+/-0.00)$ & $23.00(+/-16.61)$ & $2.89 \mathrm{e}-02(+/-2.95 \mathrm{e}-02)$ \\
\hline Paris North & 5 & 2 & 3 & $0.60(+/-0.00)$ & $1.80(+/-1.24)$ & $2.26 \mathrm{e}-03(+/-1.81 \mathrm{e}-03)$ \\
\hline Paris South & 5 & 2 & 5 & $0.60(+/-0.00)$ & $3.00(+/-1.87)$ & $3.76 \mathrm{e}-03(+/-2.75 \mathrm{e}-03)$ \\
\hline Captivity & 9 & 2 & 6 & $0.39(+/-0.00)$ & $2.33(+/-1.40)$ & $2.93 \mathrm{e}-03(+/-2.00 \mathrm{e}-03)$ \\
\hline Heidelberg & 9 & 2 & 2 & $0.22(+/-0.00)$ & $0.44(+/-0.43)$ & $5.58 \mathrm{e}-04(+/-6.17 \mathrm{e}-04)$ \\
\hline Barcelona & 7 & 2 & 8 & $0.29(+/-0.00)$ & $2.29(+/-1.42)$ & $2.87 \mathrm{e}-03(+/-2.04 \mathrm{e}-03)$ \\
\hline
\end{tabular}


Table S4: Genetic diversity for the microsatellite markers.

\begin{tabular}{llllrlllllll} 
Population & & \multicolumn{1}{l}{ N } & Na & Shannon I & Ho & He & uHe & F & HWE & LD \\
\hline Paris (South) & Mean & 47,278 & 8,000 & 1,653 & 0,717 & 0,754 & 0,762 & 0,048 & $7 / 18$ & $6 / 153$ \\
& SE & 0,565 & 0,700 & 0,085 & 0,022 & 0,020 & 0,021 & 0,020 & & \\
Paris (North) & Mean & 43,111 & 8,944 & 1,765 & 0,751 & 0,777 & 0,786 & 0,028 & $4 / 18$ & $28 / 153$ \\
& SE & 0,435 & 0,698 & 0,079 & 0,016 & 0,019 & 0,019 & 0,021 & & \\
Barcelona & Mean & 39,778 & 10,278 & 1,893 & 0,790 & 0,798 & 0,809 & 0,005 & $7 / 18$ & $115 / 153$ \\
& SE & 0,129 & 1,038 & 0,105 & 0,030 & 0,020 & 0,021 & 0,038 & & \\
Heidelberg & Mean & 29,722 & 7,944 & 1,648 & 0,760 & 0,745 & 0,757 & $-0,018$ & $7 / 18$ & $89 / 153$ \\
& SE & 0,109 & 0,602 & 0,082 & 0,030 & 0,023 & 0,024 & 0,018 & & \\
Captivity & Mean & 18,944 & 6,833 & 1,498 & 0,662 & 0,691 & 0,709 & 0,026 & $4 / 18$ & $16 / 153$ \\
& SE & 0,056 & 0,579 & 0,114 & 0,041 & 0,042 & 0,044 & 0,036 & & \\
\hline
\end{tabular}

Mean number of individuals (N), number of alleles (Na), Shannon's diversity Index (I), observed heterozygosity (Ho), expected heterozygosity (He), unbiased expected heterozygosity (uHe), fixation index (F) per sampling site and over all loci. Proportion of loci deviating from Hardy-Weinberg equilibrium (HWE) and proportion of pair of loci showing linkage disequilibrium (LD) per sampling site.

Table S5: Pairwise $F_{S T}$ between populations.

\begin{tabular}{ccccccc} 
Population & Marseille & Paris (South) & Paris (North) & Alger & Barcelona & Heidelberg \\
\hline Paris (South) & 0.057 & & & & & \\
Paris (North) & 0.039 & 0.042 & & & & \\
Alger & 0.067 & 0.074 & 0.046 & & & \\
Barcelona & 0.066 & 0.055 & 0.040 & 0.082 & & \\
Heidelberg & 0.103 & 0.086 & 0.079 & 0.110 & 0.044 & \\
Captivity & 0.114 & 0.087 & 0.069 & 0.112 & 0.084 & 0.131 \\
\hline
\end{tabular}

Table S6: Results of the ANCOVAs on the axes of the PCAs (conformation variables).

\begin{tabular}{|c|c|c|c|c|c|c|c|}
\hline Head/wing & Group:sex:size & Sex:size & Group:size & Group:sex & Group & Sex & Size \\
\hline Axis 1 & 0.53 & 0.46 & $2.18 \mathrm{e}-04 *$ & 0.80 & $\mathrm{x}$ & $\mathrm{x}$ & $\mathrm{x}$ \\
\hline Axis 2 & 0.24 & 8.07e-03 * & $1.64 \mathrm{e}-08 *$ & 0.30 & $\mathrm{x}$ & $\mathrm{x}$ & $\mathrm{x}$ \\
\hline Axis 3 & 0.91 & $5.66 \mathrm{e}-02$ & $8.02 \mathrm{e}-05 *$ & 0.17 & $\mathrm{x}$ & $\mathrm{x}$ & $\mathrm{x}$ \\
\hline Axis 4 & 0.29 & 0.47 & $9.81 \mathrm{e}-11 *$ & 0.27 & $\mathrm{x}$ & $\mathrm{x}$ & $\mathrm{x}$ \\
\hline Beak & Group:sex:size & Sex:size & Group:size & Group:sex & Group & Sex & Size \\
\hline Axis 1 & 0.12 & 0.58 & $5.17 \mathrm{e}-03 *$ & 0.38 & $\mathrm{x}$ & $\mathrm{x}$ & $\mathrm{x}$ \\
\hline Axis 2 & 0.14 & 0.69 & 3.67e-02 * & 0.79 & $\mathrm{x}$ & $\mathrm{x}$ & $\mathrm{x}$ \\
\hline Axis 3 & 0.79 & 0.94 & 0.49 & 0.78 & 0.14 & 0.53 & 0.62 \\
\hline Axis 4 & 0.74 & 0.65 & 0.15 & 0.45 & 0.24 & 0.23 & $6.79 \mathrm{e}-02$ \\
\hline Axis 5 & 0.21 & 0.17 & 0.37 & 0.42 & 0.13 & $3.90 \mathrm{e}-03 *$ & 0.39 \\
\hline Axis 6 & 0.39 & 0.70 & 0.43 & 0.93 & $4.36 \mathrm{e}-04 *$ & 0.26 & 0.37 \\
\hline Axis 7 & 0.32 & 0.31 & 0.16 & $3.49 \mathrm{e}-02 *$ & $\mathrm{x}$ & $\mathrm{x}$ & $\mathrm{x}$ \\
\hline
\end{tabular}


a)

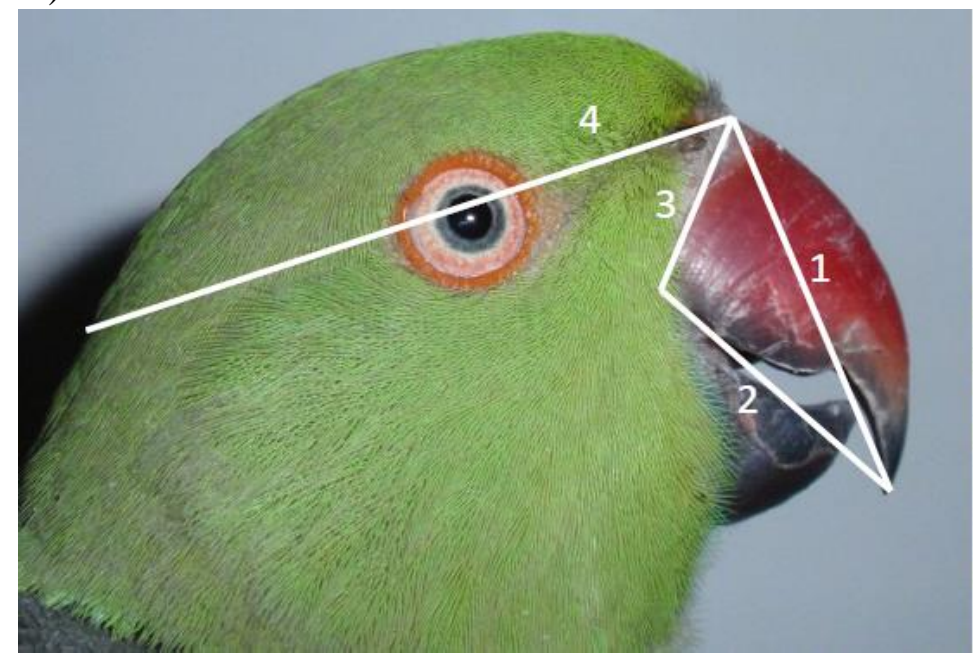

b)

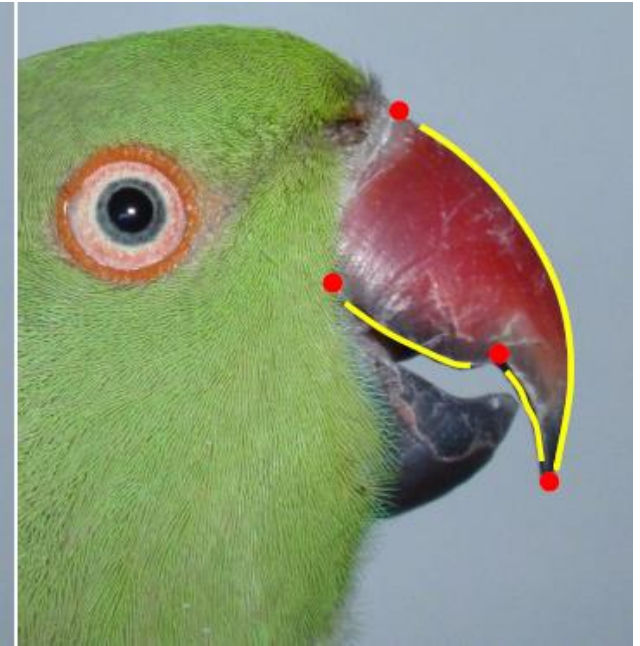

Fig. S1 a) Measurements taken on the beak of parakeets; 1: first upper mandible length, 2: second upper mandible length, 3: upper mandible depth, and 4: cranium length. Right: locations of the four landmarks and 3 outline curves (21 semi-landmarks) digitized on pictures of the beak in lateral view.

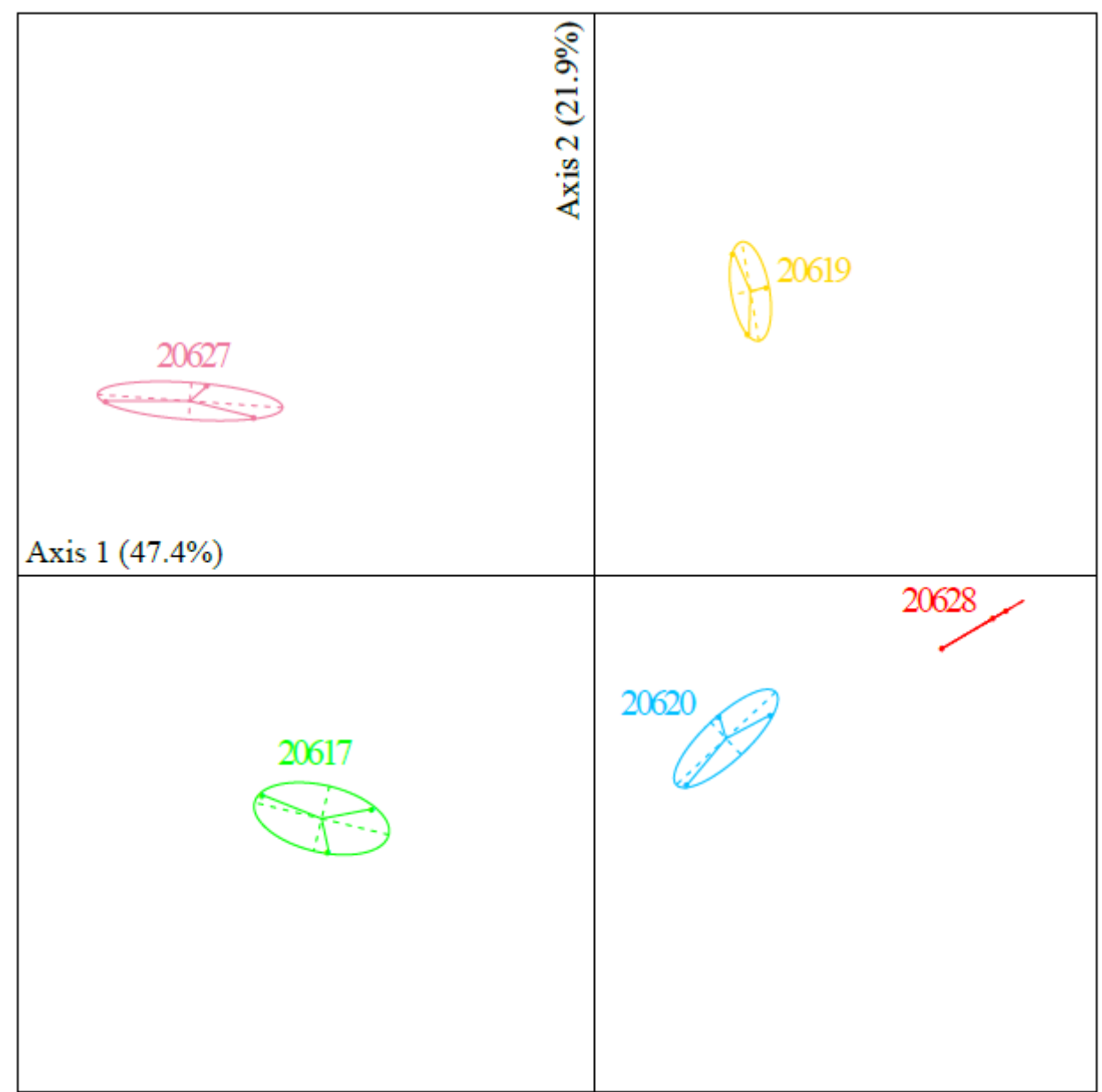

Fig. S2 PCA performed on beak conformation to test the repeatability of the digitization process. Each color represents an individual. Three repetitions where done for each of them. 


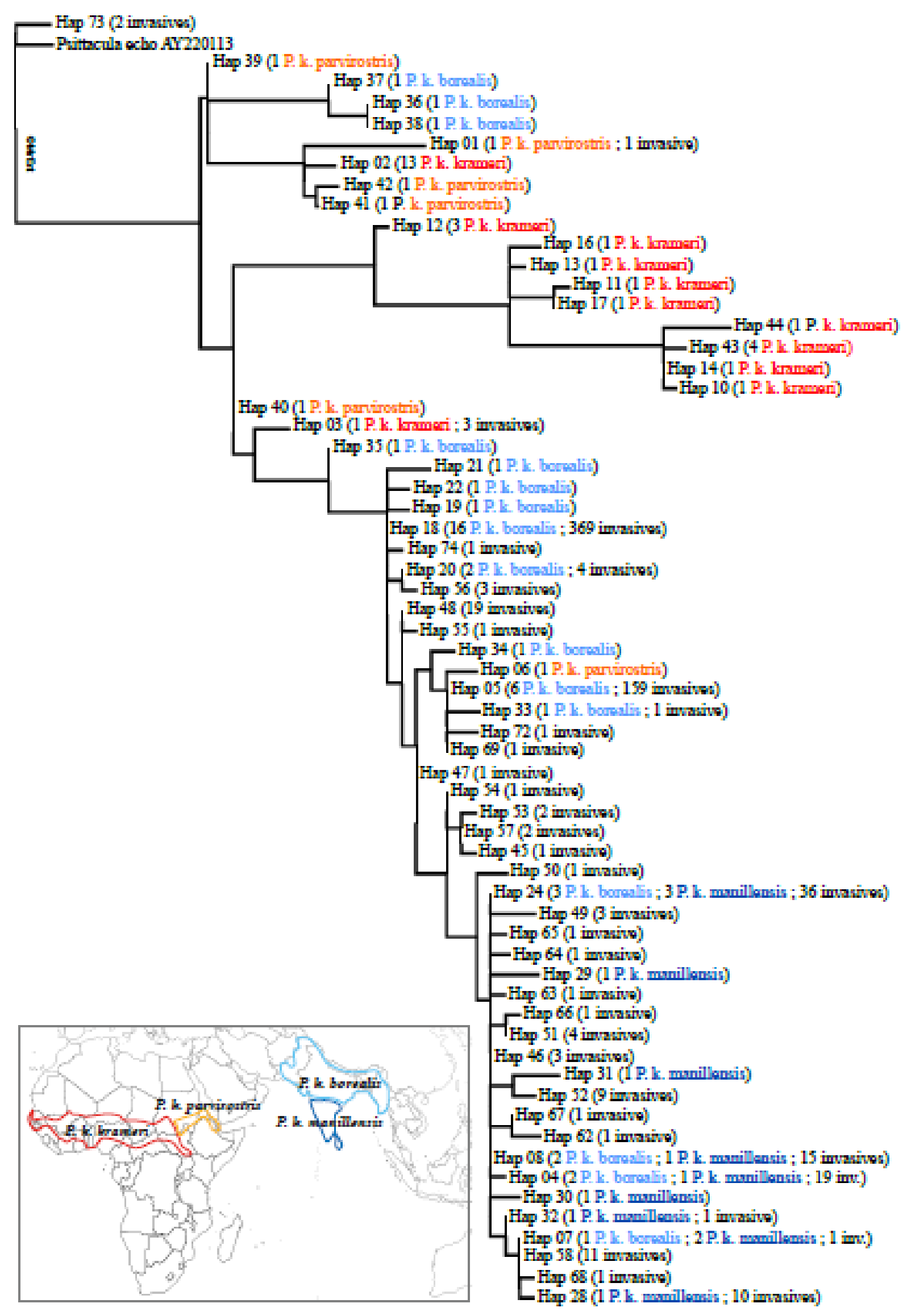

Fig. S3 The majority rule consensus tree obtained from the Bayesian analysis of the mitochondrial sequences published by Jackson et al. (2015). Colors refer to the individuals sampled in the native range. 
a)

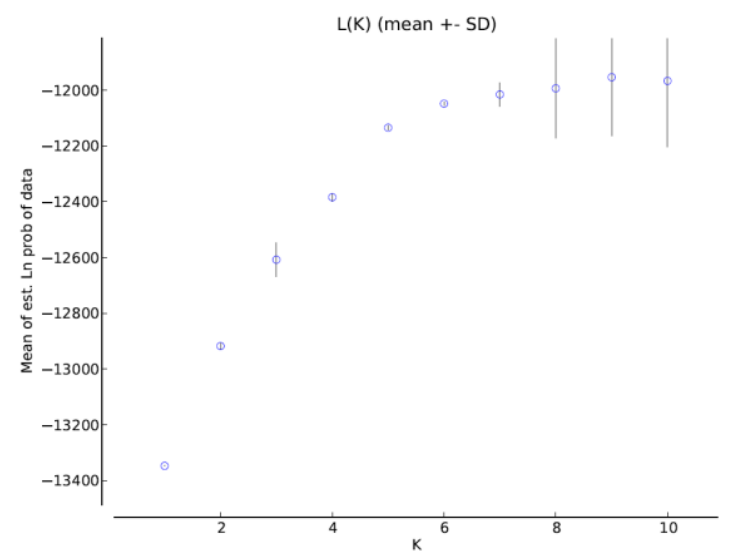

c)

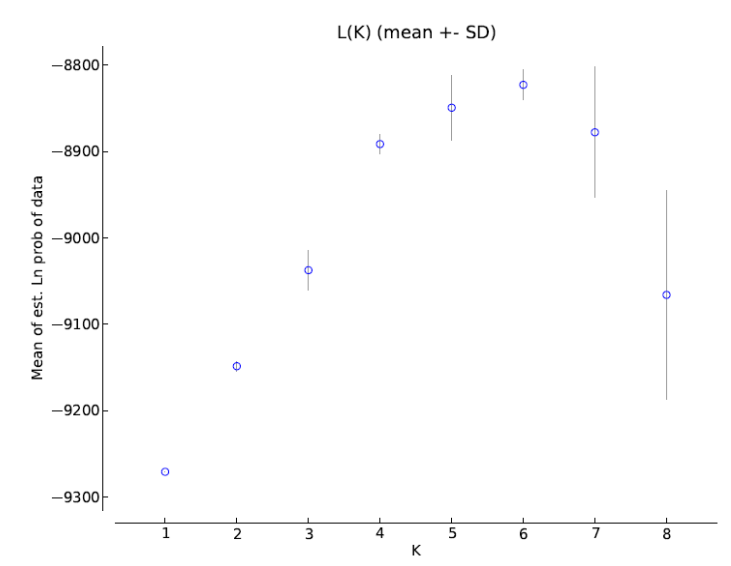

b)

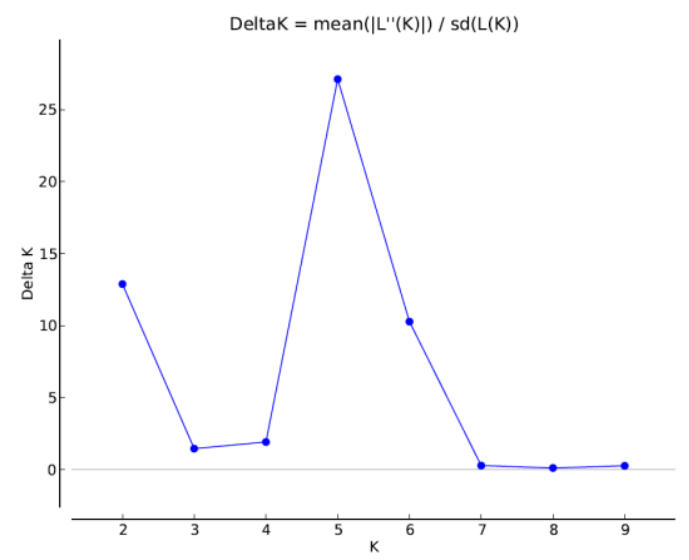

d)

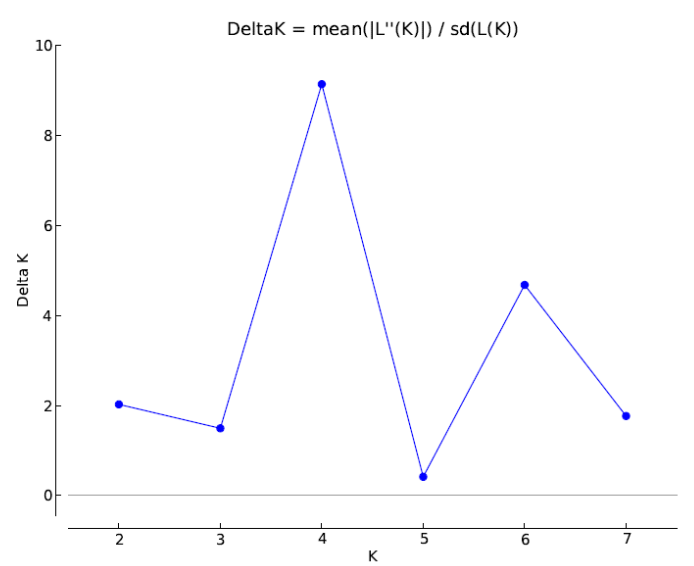

Fig. S4 Mean log-likelihood (a and c) and Delta K (b and d) calculated with STRUCTURE HARVESTER for each value of $\mathrm{K}$ and over the 10 simulations run with STRUCTURE for our data set ( $\mathrm{a}$ and $\mathrm{b}$ ) and the microsatellite data set published by Jackson et al. (2015, $\mathrm{c}$ and d). 
A - Native and invasive ranges ( 7 loci)

a)

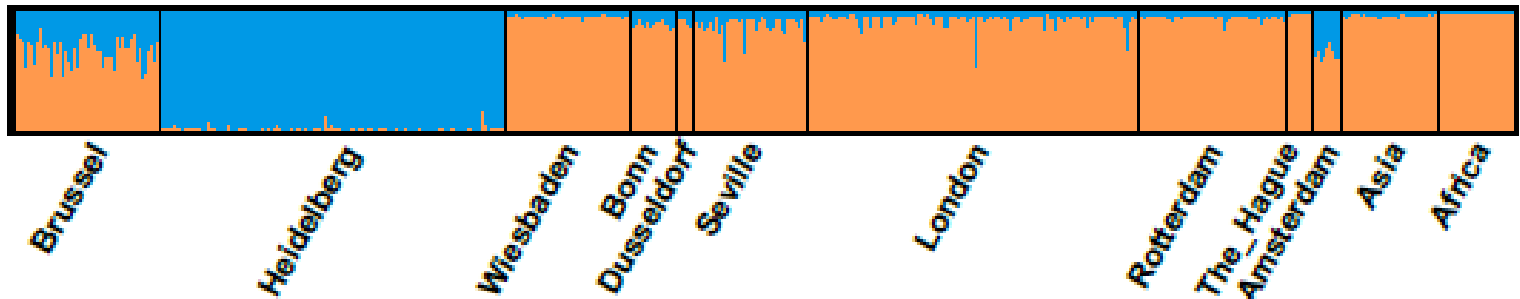

b)
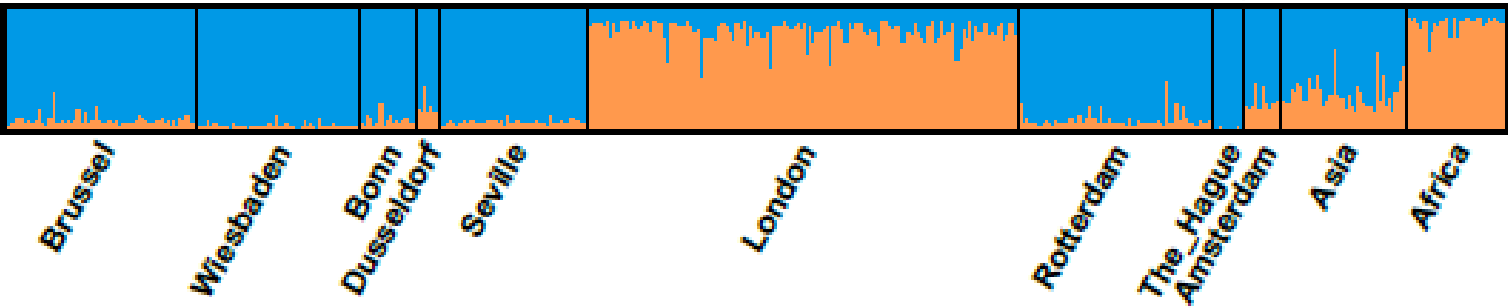

B - Invasive populations (10 loci)

c)

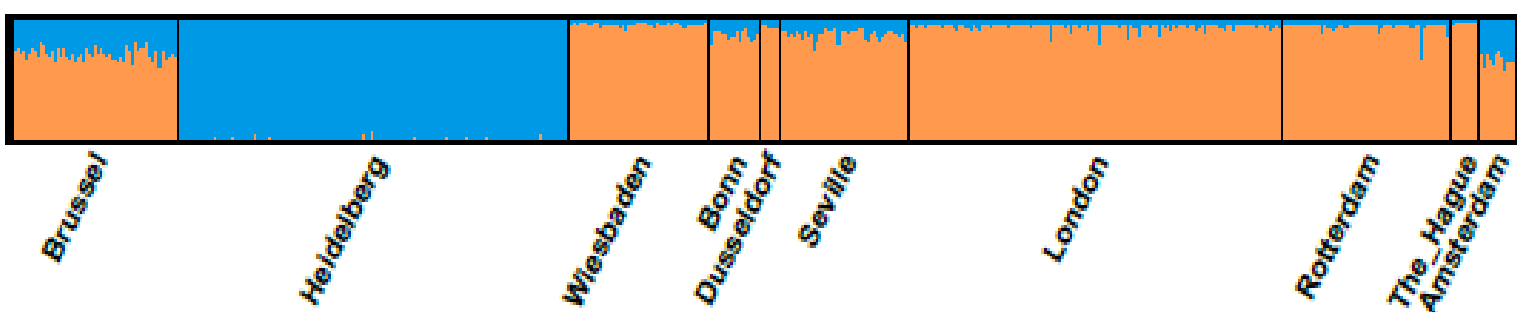

d)

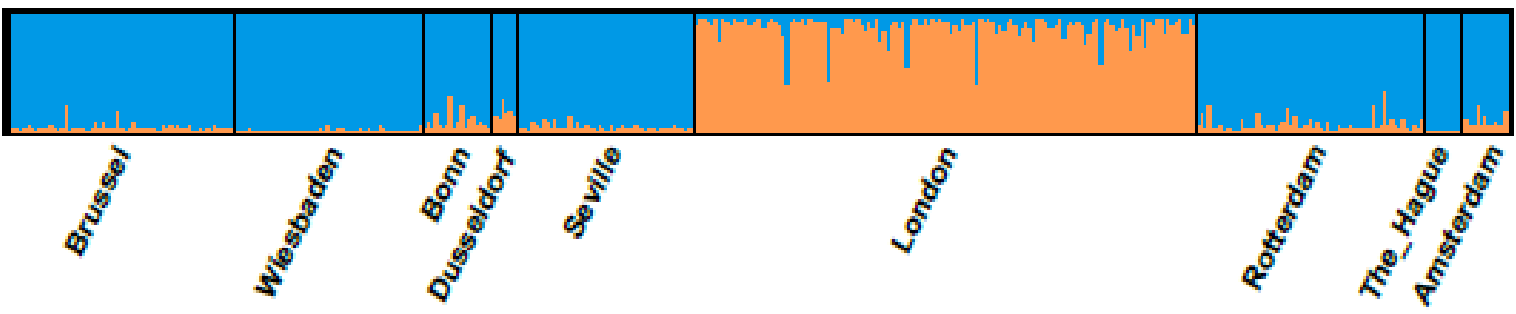

e)

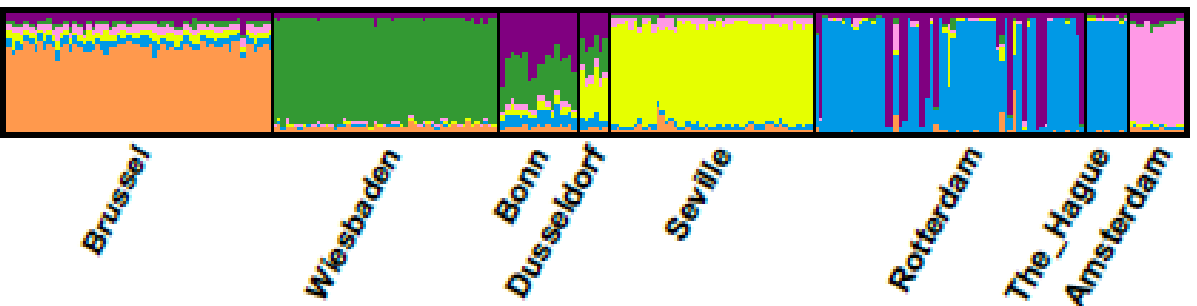

Fig. S5 Cluster assignments of individuals from the data set published by Jackson et al. (2015) obtained with STRUCTURE. The results of the 10 runs were pooled together using ClumPP (Jakobsson and Rosenberg 2007). Each vertical line represents a single individual and individuals are grouped by sampling site. 

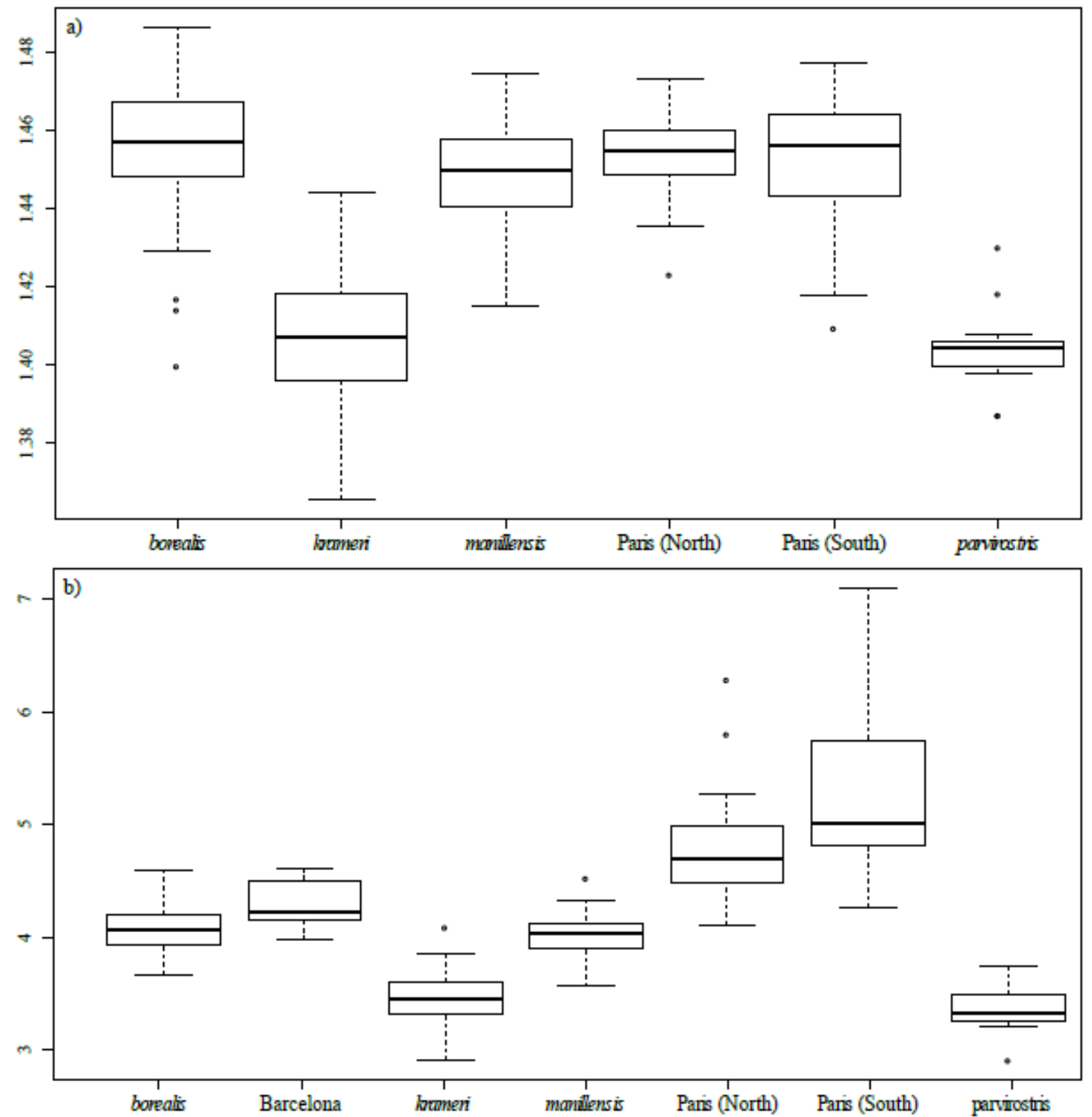

Fig. S6 boxplots of a) the overall size and b) the beak size of the individuals according to their subspecies or population. 